LM-04K036

May 6, 2004

\title{
Progress and Continuing Challenges in GaSb-based III-V Alloys and Heterostructures Grown by Organometallic Vapor Phase Epitaxy
}

CA Wang

This report was prepared as an account of work sponsored by the United States Government. Neither the United States, nor the United States Department of Energy, nor any of their employees, nor any of their contractors, subcontractors, or their employees, makes any warranty, express or implied, or assumes any legal liability or responsibility for the accuracy, completeness or usefulness of any information, apparatus, product or process disclosed, or represents that its use would not infringe privately owned rights. 
Invited Paper, $12^{\text {th }}$ International Conference on Metal Organic Vapor Phase Epitaxy

Lahaina, Hawaii, 30 May-4 June 2004

Submission for Journal of Crystal Growth

\title{
Progress and Continuing Challenges in GaSb-based III-V Alloys and Heterostructures Grown by Organometallic Vapor Phase Epitaxy
}

C.A. Wang

Lincoln Laboratory, Massachusetts Institute of Technology, Lexington, MA 02420-9108

\begin{abstract}
This paper discusses progress in the preparation of mid-IR GaSb-based III-V materials grown by organometallic vapor phase epitaxy (OMVPE). The growth of these materials is complex, and fundamental and practical issues associated with their growth are outlined. Approaches that have been explored to further improve the properties and performance are briefly reviewed. Recent materials and device results on GaInAsSb bulk layers and GaInAsSb/AlGaAsSb heterostructures, grown lattice matched to $\mathrm{GaSb}$, are presented. State-of-the-art GaInAsSb materials and thermophotovoltaic devices have been achieved. This progress establishes the high potential of OMVPE for mid-IR GaSb-based devices.
\end{abstract}

\footnotetext{
*This work was sponsored by the Department of Energy under AF Contract No. F19628-00-C-0002. The opinions, interpretations, conclusions and recommendations are those of the author and not necessarily by the United States Government.
} 


\section{Introduction}

GaSb-based III-V semiconductor alloys are attractive for optoelectronic devices such as midinfrared lasers, detectors, and thermophotovoltaics (TPVs); and electronic devices such as highspeed transistors and resonant-tunneling diodes [1]. Alloys of particular interest are based on the binaries GaSb, AlSb, InSb, GaAs, AlAs, and InAs. As shown in Fig. 1, these materials are extremely versatile III-V semiconductors from the perspective of electronic bandgap engineering and of lattice-matched or strained-layer heterostructures. The energy gap can be adjusted over a very wide wavelength range from $0.8 \mu \mathrm{m}$ for $\mathrm{AlSb}$ to $12 \mu \mathrm{m}$ for InAsSb. In addition, a variety of diverse band alignments such as type I, type II-staggered, and type II-broken [2] are possible while still maintaining nearly lattice-matched alloys to substrates, such as InP, GaSb, or InAs; or if applicable, designing deliberate strain-layer heterostructures. More recently, there has been increasing interest in GaSb quantum dots [3] and use of Sb as a surfactant in III-V growth [4].

GaSb-based heterostructures have been successfully grown by all of the major epitaxial techniques, including liquid phase epitaxy, molecular beam epitaxy (MBE), and organometallic vapor phase epitaxy (OMVPE). While each of these technologies must contend with numerous challenges that are specific to the method of choice, several fundamental issues related to Sbcontaining III-V alloys exist. These include the low volatility of Sb compared to P- and Asbased alloys, which necessitates stringent control of V/III ratio; the requirement to use low growth temperatures $\left(450\right.$ to $\left.600{ }^{\circ} \mathrm{C}\right)$; the existence of a large solid phase miscibility gap for many Sb-containing alloys; and the affinity of $\mathrm{AlSb}$-based alloys to incorporate $\mathrm{O}$ and $\mathrm{C}$. As a consequence, growth of Sb-based alloys differs significantly from the more conventional As- and P-based materials, which certainly has made the development of the GaSb-based materials and devices very challenging.

This paper discusses both the fundamental and practical issues associated with the growth of mid-IR GaSb-based III-V alloys grown by OMVPE, and briefly reviews approaches that have been explored to further improve the properties and performance of bulk layers as well as heterostructures. Growth considerations include the importance of suitable organometallic precursors and control of V/III ratio; miscibility gaps in ternary and quaternary alloys; $\mathrm{C}$ and $\mathrm{O}$ contamination in AlSb-based alloys; in-situ monitoring; GaSb substrate quality and preparation; and heterostructure growth. Recent materials and device results are limited to GaInAsSb and 
$\mathrm{AlGaAsSb}$ alloys grown lattice matched to $\mathrm{GaSb}$, since two comprehensive reviews on OMVPE growth of Sb-based materials were recently published $[5,6]$.

\section{Growth considerations and brief review of previous work}

\subsection{Fundamental differences between Sb-based and P-or As-based III-V alloys}

One of the early premises of OMVPE growth of III-V semiconductors was the utilization of precursors based on group III organometallics and group V hydrides [7]. While $\mathrm{AsH}_{3}$ and $\mathrm{PH}_{3}$ have been readily available for years, the equivalent $\mathrm{Sb}$ hydride $\mathrm{SbH}_{3}$ is not only unavailable, but also is unstable at room temperature. It was reported to boil at $-18{ }^{\circ} \mathrm{C}$ and to have a half-life of just 2 to $4 \mathrm{hr}$ at room temperature [8]. Therefore, attempts to use $\mathrm{SbH}_{3}$ have been limited to onsite synthesis and use in low-pressure OMVPE systems $[9,10]$. Because of these extremely difficult handling and stability issues, its use in OMVPE growth for Sb-based materials has been virtually non-existent since those early attempts. Only organometallic based Sb-precursors are being used in current practice. As one might anticipate, their use does not provide the advantages afforded by free $\mathrm{H}$ radicals for oxide desorption of substrates or for reducing $\mathrm{C}$ incorporation in Al-containing alloys. Therefore, both substrate preparation and C contamination can be problematic, as is discussed later in this paper.

Another major factor that differentiates the growth of Sb-based alloys from P- and As-based semiconductors is the greatly reduced volatility of $\mathrm{Sb}$ at the growth temperature compared to $\mathrm{P}$ or As. Because of the low equilibrium vapor pressure, excess $\mathrm{Sb}$ does not evaporate. Above a critical V/III ratio, an Sb-rich second phase was observed for GaSb growth [6,11-13]. On the other hand, Ga droplets formed below a critical V/III ratio. Thus, the V/III ratio must be precisely controlled around unity to avoid nonstoichimetric growth. The values of critical V/III ratios reported in the literature vary considerably, which could be due to differences in reactor designs; operating conditions such as temperature, pressure and flow rates; or to variations in vapor pressure values used for precursors. Nevertheless, to give an example of the very narrow window required for acceptable morphology, it was found that metal droplets were observed for GaSb growth with V/III $=0.8$, while the surface was featureless with V/III $=0.9$, but exhibited morphological defects with $\mathrm{V} / \mathrm{III}=1.2$ [13]. Furthermore, the low equilibrium vapor pressure of $\mathrm{Sb}$ at the growth temperature results in a near unity sticking coefficient, which can impact the 
growth of ternary and quaternary alloys. In addition, Sb surface segregation can be problematic in the growth of heterostructures.

\subsection{Alternative precursors}

While the above issues are significant, perhaps even more critical in determining the quality of Sb-containing III-V materials is the choice of starting precursors. In fact, OMVPE growth of these alloys historically has lagged behind MBE growth, primarily because of the limited availability of group III and group V precursors that are particularly suitable for Sb-based materials growth. Some of the precursor requirements are again due to fundamental differences between the Sb-based materials and P- and As-based III-V semiconductors. The low-bandgap GaSb-based alloys have low melting points and typically necessitate growth at temperatures below 550 to $600{ }^{\circ} \mathrm{C}$, which is about 100 to $250{ }^{\circ} \mathrm{C}$ lower than those compared to the higherbandgap P- and As-based III-V semiconductors. At these low temperatures, it was shown that GaSb grown with conventional precursors such as trimethylgallium (TMGa) and trimethylantimony (TMSb), resulted in kinetically limited growth since TMGa is incompletely pyrolized [13]. On the other hand, when triethylgallium (TEGa) was used, growth was masstransport limited. Since temperature variations of just a few degrees can affect the extent of precursor decomposition, which in turn could result in non-uniform alloy composition and thickness, especially over large area substrates, TEGa is currently preferred for growth of GaSb as well as for GaSb-based ternary and quaternary alloys [13-22]. Similarly, when trimethylaluminum (TMAl) was used for $\mathrm{AlGa}(\mathrm{As}) \mathrm{Sb}$, the incorporation of Al suggested that the TMAl was incompletely pyrolyzed at the growth temperature $[23,24]$.

It is equally important for the group $\mathrm{V}$ precursor to decompose at the growth temperature. $\mathrm{TMSb}$ has a pyrolysis temperature of about $550^{\circ} \mathrm{C}$ [7], and is inefficiently decomposed under typical growth conditions. Therefore, significant efforts were made to investigate alternative $\mathrm{Sb}$ precursors with lower pyrolysis temperatures [13-17,19,20,25-29]. Some of these included triethylantimony (TESb), triisopropylantimony, diisopropylantimonyhydride, tertiarybutyldimethylantimony, and trisdimethylaminoantimony (TDMASb). Many of these alternative Sb precursors were largely developed for InSb growth, which is typically grown below $450{ }^{\circ} \mathrm{C}[25,26]$. An additional benefit of these alternative precursors is that the decomposition does not produce methyl radicals, and thus can minimize levels of carbon contamination. This is particularly important for Al-containing alloys. Conversely, these 
alternative precursors are intentionally designed to decompose at low temperatures, and so they also tend to be more reactive. Parasitic reactions between $\mathrm{Sb}$ precursors and conventional group III precursors have been observed [13,29] and so the use of many of these alternatives has been limited. In practice, the main Sb precursors used for GaSb-based materials are TESb and TMSb. Electrical and optical properties of $\mathrm{GaSb}$ that is grown with various combinations of $\mathrm{TMGa}$, TEGa, TMSb, and TESb are comparable to MBE-grown materials $[12,13,18,30]$.

\subsection{Phase separation}

Even if ideal precursors were available, another fundamental challenge is related to the thermodynamics of Sb-based III-V ternary and quaternary alloys. Stringfellow reported the existence of a large solid phase miscibility gap For Sb-based alloys [31]. The atomic size and electronegativity differences between the constituent elements result in a large positive enthalpy of mixing, and equilibrium growth of the solid solution can only be achieved above a critical temperature $T_{c}$, where the negative entropy of mixing exceeds the enthalpy. The values of $T_{c}$ for $\mathrm{Al}_{\mathrm{x}} \mathrm{Ga}_{1-\mathrm{x}} \mathrm{As}_{\mathrm{y}} \mathrm{Sb}_{1-\mathrm{y}}, \mathrm{Ga}_{\mathrm{x}} \mathrm{In}_{1-\mathrm{x}} \mathrm{As}_{\mathrm{y}} \mathrm{Sb}_{1-\mathrm{y}}$, and $\mathrm{InP}_{\mathrm{x}} \mathrm{As}_{\mathrm{y}} \mathrm{Sb}_{1-\mathrm{x}-\mathrm{y}}$ are 964, 1428, and $1319 \mathrm{~K}$, respectively. These temperatures are considerably higher than typical growth temperatures. As a result, alloys have a tendency towards phase separation into microscopic regions of non-uniform alloy composition. Certainly, these non-uniformities are undesirable since such compositional variations are associated with degradation in structural, optical, and electrical properties.

On the other hand, it has also been shown that the use of non-equilibrium techniques like OMVPE and MBE can be used to grow metastable alloys within the miscibility gap [23,31-34]. Materials characteristics are significantly different depending on growth conditions, and although phase separation cannot be completely eliminated, the degree of phase separation can be greatly influenced by growth kinetics. For example, the onset of the deterioration in optical and structural properties was reported to depend on the atomic surface step structure, which is sensitive to growth temperature, growth rate, and substrate misorientation [34]. The importance of growth kinetics and surface step structure on growth of metastable GaInAsSb alloys is discussed further in this paper.

\subsection{Carbon incorporation in AlSb-containing alloys}

$\mathrm{Al}(\mathrm{Ga})(\mathrm{As}) \mathrm{Sb}$ has a larger bandgap and smaller index of refraction compared to GaInAsSb,

and is extremely effective for providing carrier confinement and optical waveguiding [35]. This alloy is integral to many heterostructure optoelectronic devices, and so it is of paramount 
importance that these alloys have high quality. Due to both fundamental and practical reasons, however, growth of AlSb-containing alloys by OMVPE continues to be the most challenging material of the GaSb-based alloys. The major difficulty in OMVPE growth of AlSb-containing materials is $\mathrm{C}$ contamination, which results from the strong affinity of $\mathrm{Al}$ for $\mathrm{C}$ [36]. The use of conventional methyl-based OM sources such as trimethylaluminum is especially problematic since the levels of $\mathrm{C}$, which is a p-type impurity, is as high as $\sim 1 \times 10^{18} \mathrm{~cm}^{-3}$ even for alloys that contain only about $20 \% \mathrm{Al}[37,38]$. Corresponding hole mobility was less than $200 \mathrm{~cm}^{2} / \mathrm{V}$-s. Furthermore, the hole concentration could not be compensated by n-type dopants [37], thus precluding $\mathrm{p}-\mathrm{n}$ heterostructure devices. C incorporation is further exacerbated by the use of $\mathrm{TMSb}$, which generates methyl radicals; the lack of $\mathrm{H}$ radicals, which can mitigate $\mathrm{C}$ incorporation; and the necessity to use low V/III ratios.

Reducing $\mathrm{C}$ impurities in AlSb-containing alloys has been a major focus and alternative $\mathrm{Al}$ precursors such as triisobutylaluminum [39], tritertiarybutylaluminum (TTBAl) [13,15,19,22,24,40-42], triethylaluminum [16] trimethylamine alane (TMAAl) or dimethylamine alane (DMEAAl) [20,22,24,43,44] have been studied. Further benefits in keeping C incorporation to a minimum in $\mathrm{AlGa}(\mathrm{As}) \mathrm{Sb}$ alloys can be gained by using TEGa and TESb instead of TMGa and TMSb, respectively. C levels in AlSb grown with DMAAl or TTBAl were about $1-2 \times 10^{18} \mathrm{~cm}^{-3}$ when TESb was used as the Sb precursor $[15,43]$, compared to $10^{19} \mathrm{~cm}^{-3}$ with TMSb [15]. However, AlSb layers grown with TESb had higher levels of $O$ on the order of $6 \times 10^{19} \mathrm{~cm}^{-3}$, which was about 4 times higher than those grown with TMSb. In addition, an Al memory affect was considered problematic, and may have been related to pre-reactions between TTBAl and TESb $[15,45,46]$. Likewise, DMEAAl was reported to pre-react, but O levels were as low as $10^{17} \mathrm{~cm}^{-3}$ [24]. However, O levels were reported to be dependent on the batch of organometallic precursors $[19,24,46]$. This variability in source purity has further impeded progress in growth of AlSb-containing alloys. Furthermore, it has been difficult to measure electrical properties of AlSb-containing alloys because high levels of $\mathrm{O}$ make the alloy semiinsulating $[37,43]$.

In spite of $\mathrm{C}$ and $\mathrm{O}$ impurities, $\mathrm{AlGaSb}$ layers grown with TTBAl and TMSb have reasonable hole concentration and mobility values, as shown in Fig. 2 for $\mathrm{Al}_{\mathrm{x}} \mathrm{Ga}_{1-\mathrm{x}} \mathrm{Sb}$ [15]. The hole concentration is $\sim 1 \times 10^{17} \mathrm{~cm}^{-3}$ for $\mathrm{x}=0.2$, and increases to $3.8 \times 10^{18} \mathrm{~cm}^{-3}$ for $\mathrm{x}=1$. The corresponding mobility values are $\sim 780$ and $100 \mathrm{~cm}^{2} / \mathrm{V}$-s, respectively. These values are 
considerably better than the values measured for layers grown with TMAl (shown as the open symbols in Fig. $2[37,38])$. The use of TEGa and TMAAl resulted in a hole concentration as low as $9.4 \times 10^{17} \mathrm{~cm}^{-3}$ (no mobility value was reported)[43]. A slight benefit of adding As in the layer through the use of tertiarybutylarsine (TBAs) or $\mathrm{AsH}_{3}$ was shown to reduce the hole concentration $[38,43,46] . \mathrm{AlAs}_{0.16} \mathrm{Sb}_{0.84}$ was reported to have hole concentrations over an order of magnitude lower than AlSb $[43,46]$.

An important breakthrough for AlSb-containing epilayers was the ability to the dope the alloys n-type [40,41,43], and the demonstration of electrically pumped p-n diode lasers [4042,47]. Both diethyltellurium [41] and tetraethyltin [43] were used as successful n-type doping sources and $\mathrm{n}-\mathrm{AlGaAsSb}$ epilayers were grown over the entire $\mathrm{Al}$ alloy range. The electron concentration ranged from about $1 \times 10^{16}$ to $6 \times 10^{17} \mathrm{~cm}^{-3}$; it decreased as the $\mathrm{Al}$ content increased because of the higher $\mathrm{C}$ levels [40].

Currently, the most suitable combination of precursors for OMVPE growth of AlSbcontaining materials is either TTBAl or DMEAAl with TMSb or TESb. However, the best combination certainly depends on the reactor configuration and gas handling system.

\subsection{In-situ diagnostics}

In-situ monitoring of the epitaxial growth can provide insight into fundamental processes, and it has been shown to be extremely useful in understanding technical challenges often associated with the growth of Sb-based III-V materials. A variety of optical techniques exist for probing OMVPE growth, each sensitive to different parameters of interest [45,48-57]. Fourier transform infrared spectroscopy (FTIR) [45] and ultraviolet spectroscopy [48,49] were used to monitor the gas phase concentration of precursors. FTIR showed that TTBAl was contaminated with isobutane and isobutene, and that the bubbler had to be purged for hours to dilute these gaseous impurities. Furthermore, it was used to monitor parasitic gas-phase pre-reactions between new combinations of precursors. Spectral reflectance [50-52], surface photoabsorption spectroscopy $[53,54]$, and reflectance difference spectroscopy $[55,56]$ have been used to monitor growth rate, alloy composition, Sb surface segregation, interfacial layers, doping levels, and desorption of surface oxides. Spectral reflectance was adapted from systems used for in-situ monitoring of As- and P-based materials [57], but because of the smaller bandgap of the GaSbbased alloys, absorption by the optical probe can be significant. Therefore for spectral 
reflectance monitoring, wavelengths longer than about $\sim 750 \mathrm{~nm}$ are necessary to determine growth rate and optical constants from classical Fabry-Perot interference oscillations [50].

\subsection{GaSb substrates}

The availability of high-quality substrates is central to the development of any epitaxial growth process. Although the lattice constant of InAs is very similar to that of GaSb, and InAs has also been used for mid-IR materials, GaSb substrates are preferred because a larger range of bandgaps can be achieved for GaInAsSb alloys lattice-matched to GaSb compared to InAs. Furthermore, alloys of the same bandgap and lattice matched to InAs are further in the miscibility gap [32].

The outstanding issues for GaSb substrates are the lack of semi-insulating substrates (SI); native oxides on epiready substrates; and the availability of high-quality GaSb substrates. SI GaSb substrates have been extremely difficult to produce because of its small energy gap and high concentration of native defects [1]. As a result, electrical characterization of GaSb-based epilayers is often performed on layers that are grown mismatched to SI GaAs substrates. While it is assumed that the carrier concentration will be the same for layers grown mismatched to GaAs or matched to GaSb, recent studies have shown otherwise [58]. The hole concentration in $\mathrm{GaSb}$ doped with $\mathrm{Si}$ was as much as a factor of two higher for the layers grown on $\mathrm{GaSb}$ compared to GaAs. On the other hand, the electron concentration of Te- $\mathrm{Ga}_{0.8} \mathrm{In}_{0.2} \mathrm{Sb}$ was about $20 \%$ higher on GaSb substrates. To accurately determine carrier concentration, Raman spectroscopy is being developed as a non-contact characterization method [59].

Furthermore, the lack of SI GaSb substrates (or the nearly lattice-matched InAs) has limited the development of high-speed electronic devices and on-wafer device isolation. As a result, this has motivated a variety of alternative substrate solutions. These include mismatched growth on specially designed buffer layers [60]; GaSb transfer by hydrogen implantation [61]; lateral epitaxial overgrowth [62]; and wafer bonding [63,64] or wafer fusion [65] followed by epitaxial transfer.

Epi-ready GaSb substrates are highly desirable for growth. However, recent studies using insitu reflectance and ex-situ atomic force microscopy (AFM), combined with analysis of the chemistry and kinetics of native oxides of GaSb, have shown that thermal desorption of native oxides can lead to surface roughening $[51,66]$. Therefore, a recommendation was made that the substrate be etched prior to growth. Figure 3 shows a large deviation in reflectance spectra 
during heating of $\mathrm{GaSb}$, which is attributed to oxide desorption. GaSb grown on an epi-ready substrate, where the oxide is thermally evaporated, exhibits a significantly rougher surface compared to that obtained for growth on a chemically etched substrate [51]. These observations were explained by a thermally activated reaction between $\mathrm{GaSb}$ and antimony oxide, which proceeds according to the following reaction [66]:

$$
\mathrm{Sb}_{2} \mathrm{O}_{3}+2 \mathrm{GaSb}->\mathrm{Ga}_{2} \mathrm{O}_{3}+4 \mathrm{Sb} \text {. }
$$

$\mathrm{Sb}_{2} \mathrm{O}_{3}$ is thermodynamically unstable with $\mathrm{GaSb}$, and thus will consume it and roughen the substrate surface. However, if the oxide is chemically etched and the surface is treated so that negligible surface oxide subsequently forms prior to loading into the reactor, a smoother surface can be achieved [51]. Various chemical etchants have been reported [51,67-69], and a simple etch in $\mathrm{HCl}$ is very effective for substrate preparation, yielding a root mean square roughness of 0.2 to $0.3 \mathrm{~nm}[51,69]$. It is important to note that precautions must be taken to limit the formation of native oxides in substrate preparation with the elimination of $\mathrm{H}_{2} \mathrm{O}$ in the process, as the oxidation rate of GaSb is exponentially fast [70]. An atomically smooth surface and minimal surface roughness is especially important for growth of metastable alloys since morphological undulations associated with surface roughness can enhance alloy decomposition [71], as was observed for GaInAsSb growth [69].

\section{Recent Work}

In spite of the numerous challenges discussed in the previous section, the quality of OMVPEgrown Sb-based materials has greatly improved as a result of availability and improvements in alternative precursors; the use of in-situ monitoring; and extensive materials characterization. The results presented in this section are based on epitaxial layers that were grown in a verticalrotating disk reactor, which was designed and built over 15 years ago for growth of highly uniform and reproducible GaAs-based materials and quantum-well devices [72]. The only modification that has been made to the reactor is the addition of an in-situ spectral reflectance monitor [50]. The reactor operates at 150 Torr and susceptor rotation rate was $250-450 \mathrm{rpm}$. The gas-handling system has only one switching manifold for introduction of group III and group V precursors. Growth uniformity and reproducibility of GaSb-based alloys is similar to that obtained for GaAs-based alloys. 
$\mathrm{GaInAsSb}, \mathrm{AlGaAsSb}$, InAsSb, and GaSb epitaxial layers were grown with trimethylindium, TEGa, TTBAl, TBAs, and TMSb. Diethyltellurium (DETe) and dimethylzinc (DMZn) were used as the n- and p-type doping sources, respectively. Although not explicitly discussed in section 2.2, TBAs is preferable over $\mathrm{AsH}_{3}$ since it has a lower pyrolysis temperature $[7,18,19,24,40,46,60,73]$. It was found that alloy uniformity and reproducibility was better with TBAs than $\mathrm{AsH}_{3}$. The growth temperature for GaInAsSb ranged from 525 to $575{ }^{\circ} \mathrm{C}$, while it was 525 or $550{ }^{\circ} \mathrm{C}$ for AlGaAsSb. (001) GaSb substrates miscut $6^{\circ}$ toward (1-11)B were typically used since it was found that the material quality of metastable GaInAsSb was significantly better than layers grown on substrates with smaller miscut angles and miscut directions toward (111)A and (101).

\subsection{Effect of growth kinetics on phase separation in GaInAsSb}

The primary concern for growth of GaInAsb alloys is the ability to achieve compositionally uniform epilayers, since this materials system exhibits a large miscibility gap [31]. Systematic experiments have shown that phase separation in GaInAsSb epilayers can be greatly reduced by affecting growth kinetics so that adatom surface diffusion is limited. It was found that growth temperature, growth rate, and substrate miscut had a large impact on structural and optical qualities [34,74-77]. This huge sensitivity of material quality to growth conditions is demonstrated by comparing characterization data of two GaInAsSb layers that were grown at a different temperature. The results for GaInAsSb grown at 525 or $575^{\circ} \mathrm{C}$ on (001) GaSb miscut $2^{\circ}$ toward (101) are shown in Figs. 4 and 5, respectively. Figures 4a, 4b, 4c, and 4d show AFM, high-resolution x-ray diffraction (HRXRD), cross-sectional transmission electron microscopy (XTEM), and photoluminescence (PL) data, respectively, for 0.50-eV GaInAsSb grown at $525^{\circ} \mathrm{C}$. Figures $4 \mathrm{a}-4 \mathrm{~d}$ are the corresponding characterization data for 0.55-eV GaInAsSb grown at $575^{\circ} \mathrm{C}$ on a similar type of $\mathrm{GaSb}$ substrate. The alloy composition that corresponds to $0.5-\mathrm{eV}$ $\mathrm{GaInAsSb}$ is further into the miscibility gap than $0.55-\mathrm{eV}$ GaInAsSb.

The data in Fig. 4 are indicative of excellent material quality. The AFM scan (Fig. 4a) shows a vicinal surface and implies step-flow growth. The full-width at half-maximum (FWHM) in the HRXRD of the epilayer and substrate peaks (Fig. 4b) is comparable. Uniform contrast in the XTEM image (Fig. 4c) suggests alloy uniformity. Further confirmation of the high quality is presented in the 300 and $4 \mathrm{~K}$ PL spectra (Fig. 4d). The 4-K PL FWHM is $9.5 \mathrm{meV}$. The 4-K PL 
peak energy is about $0.07 \mathrm{eV}$ higher than the $300-\mathrm{K}$ PL peak energy, in line with the expected $\mathrm{E}_{\mathrm{g}}$ dependence on temperature.

In contrast, GaInAsSb grown at a higher temperature of $575^{\circ} \mathrm{C}$ exhibits an irregular surface step structure (Fig. 5a), a very broad HRXRD curve (Fig. 5b), strong contrast modulation in XTEM (Fig. 5c), and anomalous PL (Fig. 5d). Both the 4- and 300-K PL spectra are broadened, and the 4-K PL peak energy is red shifted with respect to the peak at $300 \mathrm{~K}$. The $300-\mathrm{K}$ PL peak occurs at $2235 \mathrm{~nm}$, and significant PL intensity is still observed as far out as $2800 \mathrm{~nm}$. The collective characterization results are indicative of significant compositional nonuniformity. PL broadening most likely is due to the compositional inhomogenities associated with phase separation. Carriers recombine in the compositionally nonuniform, lower- $\mathrm{E}_{\mathrm{g}} \mathrm{InSb}$-rich regions. Energy-dispersive x-ray analysis in a scanning transmission electron microscope confirmed that lighter regions are InSb-rich, while darker regions are GaAs-rich [77]. Reciprocal space mapping in HRXRD studies indicated that the broadening is also due to epilayer tilt [76].

Measurement of 4-K PL FWHM values is a relatively quick method to semiquantitatively assess the degree of phase separation for these nominally undoped, lattice-matched GaInAsSb epilayers: FWHM values increase with alloy nonuniformity associated with phase separation. Figure 6 summarizes these values as a function of the 4-K PL peak energy for GaInAsSb grown nominally lattice matched to $\mathrm{GaSb}$ at 525,550 , and $575^{\circ} \mathrm{C}$. (Data are only shown for those samples with a blue-shifted 4-K PL peak energy compared to the $300-\mathrm{K}$ energy.) The PL FWHM values strongly depend on both growth temperature and PL peak energy. In general, the PL FWHM values decrease with decreasing growth temperature, and increase with decreasing PL peak energy. The smallest PL FWHM values are obtained for layers grown at the lowest temperature of $525^{\circ} \mathrm{C}$, and are as low as $4.3 \mathrm{meV}$ for $\mathrm{Ga}_{0.89} \mathrm{In}_{0.11} \mathrm{As}_{0.09} \mathrm{Sb}_{0.91}$ with 4-K PL energy at $0.666 \mathrm{eV}$ (corresponding $300 \mathrm{~K}$ energy at $0.593 \mathrm{eV}$ ) and $9.5 \mathrm{meV}$ for $\mathrm{Ga}_{0.8} \mathrm{In}_{0.2} \mathrm{As}_{0.18} \mathrm{Sb}_{0.82}$ with 4-K PL energy at $0.545 \mathrm{eV}$ (corresponding $300 \mathrm{~K}$ energy at $0.499 \mathrm{eV}$ ). For a growth temperature of $575^{\circ} \mathrm{C}$, the FWHM values increase above $20 \mathrm{meV}$ for 4-K PL energy of about $0.62 \mathrm{eV}$ and lower. The layers grown at $525{ }^{\circ} \mathrm{C}$ are on par with MBE-grown materials.

The PL FWHM dependence on energy is consistent with the fact that lower energy is associated with alloys that penetrate further into the miscibility gap. Therefore, those layers have an increased tendency to phase separate [32]. Conversely, the FWHM dependence on growth 
temperature is just the opposite from thermodynamic considerations, since increasing growth temperature should increase the entropy of the system. These results suggest that surface kinetics also play an extremely important role in the OMVPE growth and resulting quality of metastable GaInAsSb.

Additional experiments to evaluate kinetic factors were performed by variation of the growth rate and substrate misorientation angle and direction. Figure 7 shows that increasing the growth rate from 1.2 to $5 \mu \mathrm{m} / \mathrm{h}$ results in 4-K PL FWHM values being reduced by about a factor of two [75]. Similarly, it was found that the substrate miscut orientation and miscut angle affect the degree of phase separation. Figure 8 shows the reciprocal space HRXRD maps for GaInAsSb grown at $575^{\circ} \mathrm{C}$ on (001) GaSb substrates miscut $2^{\circ}$ toward (101), (1-11)B, and (-1-11)A and the corresponding PL data [76]. These layers were deliberately grown at the higher temperature to enhance phase separation. Although the GaInAsSb alloy composition is nominally the same, the degree of alloy nonuniformity depends on the substrate miscut direction. The most homogeneous alloy is obtained for GaInAsSb grown on the substrate miscut toward (1-11)B, while the least uniform is for the miscut toward (101). The kinetic tendency of GaInAsSb to phase separate was related to the temperature sensitivity of the surface step structure, anisotropic adatom surface diffusivity, and anisotropic adatom attachment at step edges. Decreasing growth temperature; increasing the adatom flux (i.e., growth rate); and increasing substrate miscut angle reduce adatom surface diffusion, and consequently limit the ability of the system to approach thermodynamic equilibrium.

\subsection{Natural superlattices in GaInAsSb}

A unique and extremely interesting manifestation of phase separation in the form of a selforganized natural superlattice structure (NSL) was observed in GaInAsSb grown nominally lattice matched to vicinal GaSb substrates [78], and in AlGaInAsSb grown on (001) InP [79]. The NSL is shown in Figure 9 in the [110] XTEM image of 0.5-eV GaInAsSb grown on (001) GaSb mismatched $6^{\circ}$ toward (1-11)B. [78]. The NSL has a period of $20 \mathrm{~nm}$, which was found to be dependent on the growth temperature and alloy composition. The NSL is detected at the onset of growth and extends both laterally and vertically over several microns. Furthermore, the $\mathrm{NSL}$ is inclined by an additional $4^{\circ}$ with respect to the $(001)$ terrace of the vicinal $\mathrm{GaSb}$ substrate. Spinodal-like contrast is also observed. The tilted NSL intersects the surface of the epilayer, and the NSL period is geometrically correlated with the periodicity of surface 
undulations. While the underlying driving force for this phase separation arises from solution thermodyamics, the mechanism for the self-organized microstructure is related to local strains associated with surface undulations. This study illustrates the complex interactions between compositional modulations and morphological perturbations and underscores the importance of atomically smooth substrates for growth of metastable alloys [69].

\section{$3.3 \quad G a(\operatorname{In})(A s) S b / A l(G a)(A s) S b$ Heterostructures}

The electronic and optical properties of $\mathrm{Ga}(\mathrm{In})(\mathrm{As}) \mathrm{Sb} / \mathrm{Al}(\mathrm{Ga})(\mathrm{As}) \mathrm{Sb}$ heterostructures ultimately determine device performance, and therefore, the structural quality of the interface is important. Growth and characterization studies of superlattice and multiple-quantum-well (MQW) structures in GaSb-based materials have revealed that the quality of heterointerfaces in Sb-containing alloys is extremely sensitive to growth switching sequences. Interruptions during OMVPE growth were reported to alter the interface chemistry and degrade the interface structure $[47,52,80,81]$. Even with growth interruption of only a few seconds, interfaces in $\mathrm{GaSb} / \mathrm{GaAs}$ $\mathrm{GaSb} / \mathrm{Al}(\mathrm{Ga}) \mathrm{Sb}$ and MQW structures were compositionally graded [16,22,46,55,81]. The grading was attributed to memory effects associated with the Al precursor $[16,22,46]$ or to Sb surface segregation [55].

\subsubsection{GaInAsSb/GaSb MQW structures}

We recently studied the effects of interruption on interface quality by monitoring the stability of epilayer surfaces with in-situ reflectance, and also by growing GaInAsSb/GaSb MQW structures [52]. It was found that both interruption time and ambient atmosphere significantly impact the stability of the GaInAsSb surface. The reflectance was most stable with only a very low partial pressure of $\mathrm{Sb}$, on the order of 10 times lower than that used during epilayer growth. Any partial pressure of As, even in combination with $\mathrm{Sb}$, significantly degraded the reflectance. On the other hand, GaSb and AlGaAsSb were comparatively unaffected by interruption time or partial pressure of TMSb.

A five-period MQW structure consisting of $10 \mathrm{~nm}$ GaInAsSb wells and $40 \mathrm{~nm}$ GaSb barriers was grown with various interruption sequences. An interruption was introduced after growth of each GaInAsSb well, and the interruption time was either 0.2 or $60 \mathrm{~s}$ and the ambient was either $\mathrm{H}_{2}$ or $1 \times 10^{-4}$ mole fraction TMSb in the $\mathrm{H}_{2}$ carrier. Figures $10 \mathrm{a}$ and $10 \mathrm{~b}$, respectively show the HRXRD and 4-K PL data. Very good agreement between the measurement (upper) and simulation (lower) HRXRD curves is observed. This result indicates the high structural quality 
and compositionally abrupt interfaces of the structure. The optical quality is more sensitive as seen in Figure 10b. The highest PL intensity is observed for the sample with the shortest interruption time of $0.2 \mathrm{~s}$ with TMSb. Increasing the TMSb interruption time reduces the PL intensity. The lowest PL efficiency is observed for the sample with $60 \mathrm{~s} \mathrm{H}_{2}$ interruption. All samples have similar FWHM values of about $9 \mathrm{meV}$. However, the PL peak position shifts to shorter wavelengths with the decrease in PL intensity. Since a lower As or In content would decrease the PL wavelength, this shift may be related to a loss of As or In at the surface. It is likely that interface states, which are non-radiative recombination centers, result from growth interruption and are responsible for this decrease in optical efficiency.

\subsubsection{AlGaAsSb/GaSb distributed Bragg reflectors}

High-reflectivity mirrors are important for optoelectronic devices such as vertical-cavity surface-emitting lasers and resonant cavity photodetectors. While AlGaAsSb/(Al)Ga(As)Sb quarter-wave distributed Bragg reflectors (DBRs) are of interest for mid-IR GaSb optelectronics, they are particularly attractive for near-IR InP-based devices because these alloys have a larger index contrast than InP-based materials $(\Delta \mathrm{n} \sim 0.6$ compared to 0.4$)$. Furthermore, these alloys can be lattice matched to the InP substrate. Consequently, fewer periods of the AlSb-based materials are needed to obtain the same reflectivity as InP-based materials. Such structures have been demonstrated by MBE growth [82].

Since a majority of InP-based optoelectronic devices are grown by OMVPE, it was of interest to study the potential of OMVPE for growth of AlGaAsSb/(Al)Ga(As)Sb DBRs. DBR structures consisting of a 10-period stack of $\mathrm{Al}_{0.81} \mathrm{Ga}_{0.19} \mathrm{As}_{0.06} \mathrm{Sb}_{0.94} / \mathrm{GaSb}$ was grown at $550{ }^{\circ} \mathrm{C}$ on GaSb. The structures were lattice-matched to GaSb substrates for convenience, and it is anticipated that structures could be similarly developed for InP. In-situ reflectance monitoring was used to calibrate growth rates and alloy composition [50], since accurate and reproducible layer thickness and composition must be accurately controlled for high-reflectivity DBR structures.

Figure 11a shows the measured (upper) and simulated (lower) x-ray diffraction curves for a DBR structure. The simulation suggested layer thickness of 163.6 and $143.1 \mathrm{~nm}$ for AlGaAsSb and $\mathrm{GaSb}$, respectively, and is in very good agreement with intended layer thicknesses of 157 and $143 \mathrm{~nm}$, respectively. The high-order satellite peaks are indicative of compositionally abrupt interfaces throughout the structure. The spectral reflectance measurement (solid line) and 
theoretical calculation (dashed line) are shown in Figure 11b, and the agreement between the peak reflectance, width of the stop band, and side bands is excellent. A peak reflectance of $95.2 \%$ at $2.17 \mathrm{~mm}$ was measured.

The reflectance stop band can be controlled by variation of $\mathrm{AlGaAsSb}$ and $\mathrm{GaSb}$ layer thicknesses. Figure 12 summarizes the reflectance for four DBR structures, which were designed to show the controllability that can been achieved for OMVPE growth. The center of the stop band ranges from 1.59 to $2.47 \mu \mathrm{m}$, while the peak reflectance ranges from 93 to $96 \%$ for DBRs centered at 2.0 to $2.47 \mu \mathrm{m}$, and is $87.4 \%$ for the DBR centered at $1.59 \mu \mathrm{m}$. This lower value is due to absorption in the GaSb layer of the DBR. A low value of $\mathrm{Al}$ in this larger index layer would increase the energy gap of that layer and thus decrease absorption, which will lead to increased reflectance.

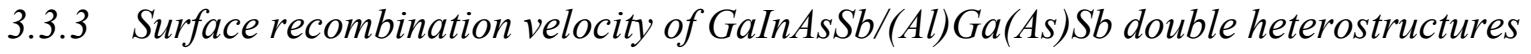

The performance of minority carrier devices such as light-emitting diodes, photovoltaics, and heterojunction bipolar transistors is sensitive to non-radiative recombination at heterointerfaces, and numerous studies aimed at minimizing surface recombination velocity have been reported for heterostructures comprised of GaAs- and InP-based III-V alloys [83]. More recently, surface recombination velocity in GaInAsSb/GaSb and $\mathrm{GaInAsSb} / \mathrm{AlGaAsSb}$ heterostructures was studied $[84,85]$. Surface recombination velocity of p-GaInAsSb doubly capped with pAlGaAsSb layers was reported to be $720 \mathrm{~cm} / \mathrm{s}$ [84]. While this value is reasonably low, significantly better values of over an order of magnitude lower have been achieved for GaAsbased materials [83]. Those GaInAsSb/AlGaAsSb structures were previously grown with interruption times on the order of minutes to accommodate growth of GaInAsSb at $525^{\circ} \mathrm{C}$ [75] and $\mathrm{AlGaAsSb}$ at $550^{\circ} \mathrm{C}$ [40]. Since these interruptions reduce the PL efficiency, we recently established growth conditions for $\mathrm{AlGaAsSb}$ at $525^{\circ} \mathrm{C}$ in order to minimize growth interruptions to a few seconds at the heterointerface [86].

The minority-carrier lifetime $\left(\tau_{\mathrm{PL}}\right)$ of samples with varying thickness $\mathrm{W}$ was measured using time-resolved PL. The data can be analyzed to determine surface recombination velocity, as previously described [83-87]. The AlGaAsSb/GaInAsSb/AlGaAsSb DHs consist of an 0.1 $\mu \mathrm{m}$ pGaSb buffer, $0.02 \mu \mathrm{m}$ p-AlGaAsSb, p-GaInAsSb (thickness varied), $0.02 \mu \mathrm{m}$ p-AlGaAsSb, and $0.025 \mu \mathrm{m} \mathrm{p}-\mathrm{GaSb}$. The p-GaInAsSb active layer was doped at $2 \times 10^{17} \mathrm{~cm}^{-3}$, and GaInAsSb thickness was varied from 0.15 to $0.4 \mu \mathrm{m}$. Three sets of DHs were grown with different 
$\mathrm{AlGaAsSb}$ concentrations, which are estimated to be about $0.2,0.25$, and 0.3 . This range of $\mathrm{Al}$ yields a hole concentration the range 1 to $5 \times 10^{17} \mathrm{~cm}^{-3}$.

The data shown in Figure 13 exhibit a linear dependence, and the surface recombination velocity is determined to be 46,27 , and $20 \mathrm{~cm} / \mathrm{s}$ for $\mathrm{Al}$ content in AlGaAsSb of 0.2, 0.25, and 0.3 , respectively. The difference in these values is probably not significant. Since previously reported values were at best $\sim 520 \mathrm{~cm} / \mathrm{s}$ [88], the benefits of minimizing growth interruption are apparent. The three sets of data yield an average $\tau_{\mathrm{BLK}}$ value of $48 \mathrm{~ns}$. Overall, $\tau_{\mathrm{PL}}$ values are slightly lower for the samples with Al content of 0.3 . SIMS analysis of bulk AlGaAsSb layers that were recently grown indicated that samples have high levels of $\mathrm{O}$ contamination on the order of 4 to $10 \times 10^{18} \mathrm{~cm}^{-3}$, with higher $\mathrm{Al}$ content alloys having higher levels of $\mathrm{O}$. These impurities create nonradiative recombination centers in Al-based III-V alloys and can degrade minority carrier lifetime. However, the surface recombination velocity was not affected. The lifetime for a GaInAsSb with GaSb capping layers also shown in Fig. 13 indicates a higher surface recombination velocity and is attributed to accumulation of electrons at the $\mathrm{GaInAsSb} / \mathrm{GaSb}$ type-II interface and to thermionic emission resulting from the lower electron confinement of GaSb confining layers [86,87].

\subsection{Devices}

By far, the majority of GaSb-based III-V emitters and detectors have been grown by MBE, primarily because of difficulties associated with OMVPE growth of AlSb-containing alloys, as discussed. Laser structures require both $\mathrm{n}$ - and $\mathrm{p}-\mathrm{Al}(\mathrm{Ga}) \mathrm{AsSb}$ layers of high $\mathrm{Al}$ content for good optical confinement. Since growth is more straightforward by MBE, there have only been a few reports of mid-IR lasers with $\mathrm{Al}(\mathrm{Ga}) \mathrm{AsSb}$ layers grown by OMVPE $[40-42,44,47,80]$. The performance of the diode lasers was promising, but it was limited by high levels of $\mathrm{O}$ in AlGaAsSb layers. The absence of any recent reports suggests little interest in pursuing mid-IR lasers using OMVPE growth.

On the other hand, OMVPE is particularly suited for the growth of GaInAsSb TPV devices, which can efficiently convert thermal energy from hot sources to electricity [89]. The thickness of the device structure is typically $5 \mu \mathrm{m}$ or more, and the high growth rates of OMVPE make it more attractive than MBE. In addition, surface passivating (window) layers, which are only $0.1 \mu \mathrm{m}$ thick, can be either AlGaAsSb or GaSb. State-of-the-art GaInAsSb/AlGaAsSb/GaSb TPV cells exhibit peak internal quantum efficiency and fill factor values exceeding $94 \%$ and 
$70 \%$, respectively $[74,88,90]$. These values, which are approaching theoretical limits, are achieved for structures grown with either $\mathrm{GaSb}$ or $\mathrm{AlGaAsSb}$ window layer. There is however, an advantage to the AlGaAsSb window layer [88,91], and the highest reported value of Voc is $0.33 \mathrm{~V}$ and was measured for devices with an AlGaAsSb window [89].

Recently, there has been interest in monolithically series-interconnected these TPV cells to build open-circuit voltage $\mathrm{V}_{\text {oc }}$; reduce parasitic losses; and simplify module assembly [92]. Since these interconnections require electrical isolation of devices, and SI GaSb substrates are not available, two different approaches for on-wafer device isolation were studied. In one study, $\mathrm{GaInAsSb} / \mathrm{GaSb}$ epilayers were grown on a lattice-matched AlGaAsSb cell-isolation diode $[60,93]$. A monolithically interconnected module (MIM) that consisted of 15 cells was fabricated, and a $\mathrm{V}_{\mathrm{oc}}$ value of $0.42 \mathrm{~V}$ was reported [93].

In another study, an alternative approach was to wafer bond the GaSb-based epilayers to a SI GaAs handle wafer, remove the GaSb substrate, and then process the wafer-bonded (WB) epitaxy $[64,9,93]$. Figure 14 schematically illustrates the WB device. The $\mathrm{SiO}_{\mathrm{x}} / \mathrm{Ti} / \mathrm{Au}$ bonding layer provides both electrical insulation and broadband high reflection. The enhanced reflectivity is used to enhance photon recycling effects and can also aid in spectral control of below bandgap photons. In processing the material, it is important to accurately remove the $\mathrm{GaSb}$ substrate without damaging the device epilayers. To insure complete removal, an InAsSb etch-stop layer (not shown) was first grown on the substrate, followed by the device layers. After bonding, the GaSb substrate is selectively etched, followed by the InAsSb etch-stop layer. The growth of the InAsSb etch-stop layer is critical, since it effectively is a buffer layer for subsequent growth [92]. It was found that the InAsSb surface can undergo significant roughening during growth interruption, and therefore, interruptions must be kept to a minimum.

The effectiveness of the internal mirror was measured by PL and time-resolved PL. Figure 15a shows that he PL intensity is about 3 times higher for the WB sample compared to the unbonded control. The normalized PL decay for WB and control GaInAsSb DHs is shown in Figure $15 \mathrm{~b}$. The lifetime measured by PL decay $\tau_{\mathrm{PL}}$ is more than two times higher at $85 \mathrm{~ns}$ for the WB sample with the internal BSR compared to the control sample with $\tau_{\mathrm{PL}}=36 \mathrm{~ns}$. These results show that photons that might normally be absorbed in the substrate are reflected back to the active layer and reabsorbed, and the internal BSR is effective in increasing minority-carrier lifetime through photon recycling. 
WB TPV devices were fabricated as shown in Figure 14. The peak external quantum efficiency of uncoated wafer-bonded TPV devices is $62 \%$, which is comparable to that of conventional TPV cells. The goal to build $\mathrm{V}_{\text {oc }}$ was achieved and results are shown in Figure 16 for a single-junction TPV cell and 2- and 10-junction series-interconnected TPV cells. At $\mathrm{J}_{\mathrm{sc}} \sim$ $0.4 \mathrm{~A} / \mathrm{cm}^{2}$, the single cell exhibits $\mathrm{V}_{\mathrm{oc}} \sim 0.2 \mathrm{~V}$. At this same current density, $\mathrm{V}_{\mathrm{oc}}$ is 0.37 and 1.8 $\mathrm{V}$ for the 2- and 10-junction devices, respectively. These results indicate that nearly linear voltage building has been achieved. At higher $\mathrm{J}_{\mathrm{sc}} \sim 1 \mathrm{~A} / \mathrm{cm}^{2}, \mathrm{~V}_{\mathrm{oc}}$ is $\sim 0.470$ and $2.0 \mathrm{~V}$ for the 2and 10-junction devices, respectively. The fill factor FF of the 2 -junction device is about $51 \%$ at $\mathrm{J}_{\mathrm{sc}} \sim 0.4 \mathrm{~A} / \mathrm{cm}^{2}$, and degrades to about $38 \%$ at $\mathrm{J}_{\mathrm{sc}} \sim 1 \mathrm{~A} / \mathrm{cm}^{2}$. This degradation is related to high series resistance in the cell-to-cell interconnections, and could be reduced with improved metallization and reduced resistance in the $\mathrm{n}-\mathrm{GaSb}$ lateral conduction layer. Further reduction in series resistance could probably be achieved by contacting the n-GaInAsSb, which can have lower contact resistivity and sheet resistance than n-GaSb [94].

\section{Conclusions}

The fundamental and practical issues associated with OMVPE growth of mid-infrared GaSbbased materials were broadly reviewed, and engineering solutions that have been explored to address these difficulties were summarized. The use of alternative precursors and exacting control of growth parameters are critical for obtaining desirable materials properties, and for establishing a reproducible growth process. Although quaternary alloys are fundamentally limited by miscibility gaps, the non-equilibrium OMVPE growth process provides effective options for affecting growth kinetics.

The present work focused on GaInAsSb alloys and GaInAsSb/(Al)Ga(As)Sb heterostructures that are lattice matched to GaSb. Temperature and growth rate are two key considerations for growth of metastable GaInAsSb alloys. The high growth rate achievable by OMVPE makes this technology extremely attractive for growth of these metastable alloys. Significant improvements in the quality of $\mathrm{AlGaAsSb}$ alloys have been made by reducing $\mathrm{C}$ incorporation. However, variability in precursor source purity has been an issue and high levels of $\mathrm{O}$ incorporation can still be problematic in AlGaAsSb alloys. Nevertheless, state-of-the-art GaInAs Sb/(Al)Ga(As)Sb heterostructures with extremely low surface recombination were demonstrated, as were AlGaAsSb DBRs. Through an iterative process of growth; use of a wide range of materials 
characterization; and concurrent evaluation of materials by testing GaInAsSb/AlGaAsSb heterostructure TPV devices, significant progress has been made in the performance of GaSbbased materials grown by OMVPE. Furthermore, there are no fundamental reasons that would prevent scaling of OMVPE growth of GaSb-based materials to larger capacity reactors.

\section{Acknowledgements}

The author gratefully acknowledges numerous individuals with expertise in growth, characterization, devices, and fabrication that have contributed to the progress in bringing OMVPE growth of GaSb-based materials to its current level. The collaborations with C.J. Vineis, H.K. Choi, D.L Spears, G.W. Turner, D.R. Calawa, J.W. Chludzinski, D.A. Shiau, D.C. Oakley R.K. Huang, M.K. Connors, P. Nitishin, P. Murphy, A. Anderson, and P. O'Brien, at Lincoln Laboratory; S. Salim, K.F. Jensen, and A. Lin at MIT; D. Donetksy, S. Anikeev, G. Belenky, and S. Luryi at Stony Brook; G.W. Charache, G. Nichols, H. Ehsani, M. Dashiell, L..R. Danielson, and D. DePoy at Lockheed Martin; I. Bhat, P. Borrego, R. Gutman, S. Saroop, and R. Kumar at RPI; and J. Maslar at NIST have been key in understanding these materials. This work was sponsored by the Department of Energy under AF Contract No. F19628-00-C-0002. The opinions, interpretations, conclusions, and recommendations are those of the authors and are not necessarily endorsed by the United States Government. 


\section{References}

1. P.S. Dutta, H.L. Bhat, and V. Kumar, J. Appl. Phys. 81 (1997) 5821.

2. A.G. Milnes and A.Y. Polyakov, Solid-State Electron. 36 (1993) 803.

3. B.M. Kinder and E.M. Goldys, Appl. Phys. Lett. 73 (1998) 1233.

4. G.B. Stringfellow, R.T. Lee, C.M. Fetzer, J.K. Shurtleff, Y. Hsu, S.W. Jun, S. Lee, T.Y. Seong, J. Electron. Mater. 20 (2000) 134.

5. A. Aardvark, N.J. Mason, and P.J. Walker, Prog. Cryst. Growth and Charact. 35 (1997) 207.

6. R.M. Biefeld, Mat. Sci. and Eng. R36 (2002) 105.

7. G.B. Stringfellow, Organometallic Vapor-Phase Epitaxy: Theory and Practice, Academic Press, San Diego, CA, 1999.

8. R.B. Clough and J.J. Tietjen, Trans. Met. Soc. AIME 245 (1969) 583.

9. O. Sugiura, H. Kameda, K. Shina, and M. Matsumura, J. Electron. Mater. 17 (1988) 11.

10. R. Menna, D.R. Capewell, R.U. Martinelli, W. Ayers, R. Moulton, J. Palmer, and G. Olsen, J. Cryst. Growth 141 (1994) 310.

11. C.B. Cooper, R.R. Saxena, and M.J. Ludowise, J. Electron. Mater. 11 (1982) 1001.

12. T. Koljonen, M. Sopanen, H. Lipsanen, and T. Tuomi, J. Electron. Mater. 24 (1995) 1691.

13. C.A. Wang, S. Salim, K.F. Jensen, and A.C. Jones, J. Cryst. Growth 170 (1997) 55.

14. R.M. Graham, A.C. Jones, N.J. Mason, S. Rushworth, L.Smith, and P.J. Walker, J. Cryst. Growth 145 (1994) 363.

15. C.A. Wang, M.C. Finn, S. Salim, K.F. Jensen, A.C. Jones, Appl. Phys. Lett. 67 (1995) 1384.

16. M. Behet, P. Schneider, D. Moulin, K. Heime, J. Woitok, J. Tummler, J. Hermans, and J. Geurts, J. Cryst. Growth 167 (1996) 415.

17. C. von Eichel-Streiber, M. Behet, M. Heuken, and K. Heime, J. Cryst. Growth 170 (1997) 783.

18. C.A. Wang, J. Cryst. Growth 191 (1998) 631.

19. Ch. Giesen, A. Szymakowski, S. Rushworth, M. Heuken, and K. Heime, J. Cryst. Growth 221 (2000) 450 .

20. R.M. Biefeld, J.G. Cederberg, G.M. Peake, and S.R. Kurtz, J. Cryst. Growth 225 (2001) 384.

21. R.D. Wiersman, J.A.H. Stotz, O.J. Pitts, C.X. Wang, M.L. W. Thewalt, and S.P. Watkins, J. Electron. Mater. 30 (2001) 1429.

22. F. Dimroth, C. Agert, and A.W. Bett, J. Cryst. Growth 248 (2003) 265. 
23. D.S. Cao, Z.M. Fang, and G.B. Stringfellow, J. Cryst. Growth 113 (1991) 441.

24. C. Agert, P. Lanyi, A.W. Bett, J. Cryst. Growth 225 (2001) 426.

25. R.M. Graham, A.C. Jones, N.J. Mason, S. Rushworth, A. Salesse, T-Y. Seong, G. Booker, L.Smith, and P.J. Walker, Semicond. Sci. Technol. 8 (1993) 1797.

26. C.H. Chen, Z.M. Fang, G.B. Stringfellow, and R.W. Gedridge, Jr. J. Appl. Phys. 69 (1991) 7605.

27. J. Shin, K. Chiu, G.B. Stringfellow, and R.W. Gedridge, Jr., J. Cryst. Growth 132 (1993) 371.

28. J. Shin, A. Verma, G.B. Stringfellow, and R.W. Gedridge, Jr., J. Cryst. Growth 151 (1995) 1.

29. J. Shin, T.C. Hsu, and G.B. Stringfellow, J. Cryst. Growth 179 (1997) 1.

30. S.K. Haywood, A.B. Henriques, N.J. Mason, R.J. Nicholas, and P.J. Walker, Semicond. Sci. and Technol. 3 (1988) 315.

31. G.B. Stringfellow, J. Cryst. Growth 58 (1982) 194.

32. M.J. Cherng, H.R. Jen, C.A. Larsen, G.B. Stringfellow, H. Lundt, and P.C. Taylor, J. Cryst. Growth 77 (1986) 408.

33. A. Zunger, S. Mahajan, S, in Handbook on Semiconductors Vol. 3, S. Mahajan (ed.) North Holland, New York, (1994) p. 1399.

34. C.A. Wang, H.K. Choi, G.W. Charache, IEE Proc. Optoelectron. 147 (2000) 193.

35. I. Vurgaftman, J.R. Meyer, and L.R. Ram-Mohan, J. Appl. Phys. 89 (2001) 5815.

36. M. Leroux, A. Tromson-Carli, P. Gibart, C. Verie, C. Bernard, and M.C. Schouler, J. Cryst. Growth 48 (1980) 367.

37. E.T.R Chidley, S.K. Haywood, R.E Mallard, N.J. Mason, R.J. Nicholas, P.J.Walker, and R.J. Warburton, J. Cryst.Growth 93 (1988) 70.

38. T. Koljonen, M. Sopanen, H. Lipsanen, and T. Tuomi, J. Cryst. Growth 169 (1996) 417.

39. A. Tromson-Carli, P. Gibart, and C. Bernard, J. Cryst. Growth 55 (1981) 125.

40. C.A. Wang, J. Cryst. Growth 170 (1997) 725.

41. C.A. Wang, K.F. Jensen, A.C. Jones, and H.K. Choi, Appl. Phys. Lett. 68 (1996) 400

42. C.A. Wang and H.K. Choi, Appl. Phys. Lett. 70 (1997) 802.

43. R.M. Biefeld, A.A. Allerman, and M.W. Pelczynski, Appl. Phys. Lett. 68 (1996) 932.

44. A.A. Allerman, R.M. Biefeld, and S.R. Kurtz, Appl. Phys. Lett. 69 (1996) 465.

45. S. Salim, C.A. Wang, R.D. Driver, and K.F. Jensen, J. Cryst. Growth 169 (1996) 443.

46. Ch. Giesen, M.M. Beerbom, X.G. Xu, and K. Heime, J. Cryst. Growth 195 (1998) 85. 
47. C.A. Wang and H.K. Choi, J. Electron. Mat. 26 (1997) 1231.

48. G.A. Hebner, K.P. Killeen, and R.M. Biefeld, J. Cryst. Growth 98 (1989) 293.

49. G.R. Booker, M. Daly, P.C. Klipstein, P.C. Lakrimi, T.F. Kuech, J. Li, S.G. Lyapin, N.J. Mason, I.J. Murgatroyd, J.C. Portal, R.J. Nicholas, D.M. Symons, P. Vicente, and P.J. Walker, J. Cryst. Growth 170 (1997) 777.

50. C.J. Vineis, C.A. Wang, K.F. Jensen, and W.G. Breiland, J. Cryst. Growth 195 (1998) 181.

51. C.J. Vineis, C.A. Wang, and K.F. Jensen, J. Cryst. Growth 225 (2001) 420.

52. C.A. Wang, D.A. Shiau, M.K. Connors, L.R. Danielson, G. Nichols, D. Donetsky, S. Anikeev, and G. Belenky, Mat. Res. Soc. Symp. Proc. Vol. 763 (2003) 315.

53. P.C. Klipstein, S.G. Lyapin, N.J. Mason, and P.J. Walker, J. Cryst. Growth 195 (1998) 168.

54. D.A. Alwood, N.J. Mason, and P.J. Walker, Mater. Sci. Eng. B66 (1999) 83.

55. O.J. Pitts, S.P. Watkins, C.X. Wang, V. Fink, and K.L. Kavanagh, J. Cryst. Growth 254 (2003) 28.

56. Z. Kollonitsch, K. Moller, H.-J. Schimper, Ch. Giesen, M. Heuken, F. Willig, and T. Hannappel, J. Cryst. Growth 261 (2004) 289.

57. W.G. Breilland and K.P. Killeen, J. Appl. Phys. 78 (1995) 6726.

58. H. Ehsani, I. Bhat, C. Hitchcock, R.J. Gutmann, G. Charache, M. Freeman, J. Cryst.Growth 195 (1998) 385.

59. J.E. Maslar, W.S. Hurst, C.A. Wang, and D.A.Shiau, to be published in MRS Fall 2003 Proceedings.

60. J.G. Cederberg, M.J. Hafich, R.M. Biefeld, M.N. Palmisiano, J. Cryst. Growth 248 (2003) 289.

61. Zheng, P.D. Moran, Z.F. Guan, S.S. Lau, D.M. Hansen, T.F. Kuech, T.E. Haynes, T. Hoechbauer, and M. Natasi, J. Electron. Mater. 29, 916 (2000).

62. S.S. Yi, D.M. Hansen, C.K. Inoki, D.L. Harris, T.S. Kuan, and T.F. Kuech, Appl. Phys. Lett. $77,842(2000)$.

63. P.D. Moran, D. Chow, A. Hunter, and T.F. Kuech, Appl. Phys. Lett. 78, 2232 (2001).

64. C.A. Wang, R.K. Huang, D.A. Shiau, M.K. Connors, P.G. Murphy, P.W. O’Brien, A.C. Anderson, D.M. DePoy, G. Nichols, and M.N. Palmisiano, Appl. Phys. Lett. 83 (2003) 1286. 65. C.A. Wang, Z.L. Liau, D.A. Shiau, and P.M. Nitishin, MRS Mat. Res. Soc. Symp., Vol. 768 (2003) 101. 
66. G.P. Schwartz, G.J. Gualtieri, J.E. Griffiths, C.d. Thurmond, and B. Schwartz, J. Electrochem. Soc. 127 (1980) 2488.

67. Z.Y. Liu, B. Hawkins, and T.F. Kuech, J. Vac. Sci. Technol. B21 (2003) 71.

68. F. W. O. Da Silva, C. Raisin, M. Silga, M. Nouaoura, L. Lassabatere, Semicond. Sci. Technol. 4 (1989) 565.

69. C.A. Wang, D.A. Shiau, and A. Lin, J. Cryst. Growth 261 (2004) 385.

70. Y. Mizokawa, O. Kodama, and S. Miyase, Thin Solid Films 156 (1988) 127.

71. 12. F. Glas, Phys. Rev. B 62 (2000) 7393.

72. C.A. Wang, S. Patnaik, J.W. Caunt, and R.A. Brown, J. Cryst. Growth 93 (1988) 228.

73. M. Sopanen, T. Koljonen, H. Lipsanen, and T. Tuomi, J.Cryst. Growth 145 (1994) 492.

74. C.A. Wang, H.K. Choi, D.C. Oakley, and G.W. Charache, J. Cryst. Growth 195 (1998) 346.

75. C.A. Wang, H.K. Choi, and G.W. Charache, IEE Proc.-Optoelectron. 147 (2000) 193.

76. C.A. Wang, D.R. Calawa, and C.J. Vineis, J. Electron. Mater. 30 (2001) 1392.

77. C.A. Wang, H.K.Choi, S.L. Ransom, G.W. Charache, L.R. Danielson, and D.M. DePoy, Appl. Phys. Lett. 75 (1999) 1305.

78. C.A. Wang, C.J. Vineis, and D.R. Calawa, to be published in MRS 2003 Fall Proceedings.

79. D.H. Jaw, J.R. Chang, and Y.K. Su, Appl. Phys. Lett. 82 (2003) 3883.

80. R.M. Biefeld, A.A. Allerman, S.R. Kurtz, and K.C. Baucom, J.Cryst. Growth 195 (1998) 356.

81. J. Tummler, J. Woitok, J. Hermans, J. Geurts, P. Schneider, D. Moulin, M. Behet, and K. Heime, J. Cryst. Growth 170 (1997) 772.

82. B. Lambert, Y. Toudic, Y. Rouillard, M.Baudet, B. Guenais, B. Deveaud, I. Valiente, and J.C. Simon, Appl. Phys. Lett. 64 (1994) 690.

83. R.K. Ahrenkiel, in Semiconductors and Semimetals, Vol. 39, ed. R.K. Ahrenkiel and M.S. Lundstrom, Acad. Press (1993) p. 39.

84. D. Donetsky, S. Anikeev, G. Belenky, S. Luryi, C.A. Wang, and G. Nichols, Appl. Phys. Lett. 81 (2002) 4769.

85. R.J. Kumar, R.J. Gutman, J.M. Borrego, P.S. Dutta, C.A. Wang, R.U. Martinelli, and G. Nichols, J. Electron. Mater. 33 (2004) 94.

86. S. Anikeev, D. Donetsky, G. Belenky, S. Luryi, C.A. Wang, D.A. Shiau, M. Dashiell, J. Beausang, and G. Nichols, $12^{\text {th }}$ Intl. Conf. on MOVPE, Lahaina, Hawaii 2004. 
87. C.A. Wang, D.A. Shiau, D. Donetsky, S. Anikeev, G. Belenky, and S. Luryi, $12^{\text {th }}$ Intl. Conf. on MOVPE, Lahaina, Hawaii 2004.

88. C.A. Wang, C.J. Vineis, H.K. Choi, M.K. Connors, R.K. Huang, L.R. Danielson, G. Nichols, G.W. Charache, D. Donetsky, S. Anikeev, and G. Belenky, AIP Conf. Proc. 653 (2003) 324.

89. G.W. Charache, P.F. Baldasaro, L.R. Danielson, D.M. DePoy, M.J. Freeman, C.A. Wang, H.K. Choi, D.Z. Garbuzov, R.U. Martinelli, V. Khalfin, S. Saroop, J.M. Borrego, and R.J. Gutman, J. Appl. Phys. 85 (1999) 2247.

90. .Z.A. Shellenbarger, G. C. Taylor, R. K. Smeltzer, J.L. Li, R. U. Martinelli, and K. Palit, AIP Conf. Proc. 653 (2003) 314.

91. H.K. Choi, C.A. Wang, G.W. Turner, M.J. Manfra, D.L. Spears, G.W. Charache, L.R. Danielson, and D.M. DePoy, Appl. Phys. Lett. 71(1997) 3758.

92. Third NREL Conference on Thermophotovoltaic Generation of Electriciy, AIP Proc. 401, 1997.

93. M.N. Palmisiano, R.M. Biefeld, J.G. Cederberg, M.J. Hafich, and G.M. Peake, AIP Conf. Proc. 653, 305-313 (2003).

94. C.A. Wang, D.A. Shiau, and D.R. Calawa, J. Cryst. Growth 261 (2004) 372.

95. C.A. Wang, D.A. Shiau, P.G. Murphy, P.W. O’Brien, R.K. Huang, M.K. Connors, A.C. Anderson, D. Donetsky, S. Anikeev, G. Belenky, D.M. DePoy, and G. Nichols, J. Electron. Mater. 33 (2004) 213.

96. C.A. Wang, D.A. Shiau, R.K. Huang, C.T. Harris, and M.K. Connors, J. Cryst. Growth 261 (2004) 379 . 


\section{List of Figures}

Figure 1. Bandgap vs. lattice constant of GaSb III-V alloys and schematic band alignments.

Figure 2. Hole concentration and mobility of $\mathrm{Al}_{\mathrm{x}} \mathrm{Ga}_{1-\mathrm{x}} \mathrm{Sb}$ measured at $77 \mathrm{~K}$ [40]. Open circles from ref. 37; open square ref. 38, filled square ref. 46, and filled triangle ref. 43.

Figure 3. In-situ reflectance of oxide desorption from (a) epiready GaSb and (b) etched GaSb [51]. The resulting surface morphology as measured by atomic force microscopy is also shown.

Figure 4. Characterization results of $0.50-\mathrm{eV}$ GaInAsSb grown at $525^{\circ} \mathrm{C}$ : (a) atomic force microscopy image, (b) high-resolution x-ray diffraction, (c) cross-sectional transmission electron microscopy, and (d) 300- and 4-K photoluminescence.

Figure 5. Characterization results of $0.55-\mathrm{eV}$ GaInAsSb grown at $575^{\circ} \mathrm{C}$ : (a) atomic force microscopy image, (b) high-resolution x-ray diffraction, (c) cross-sectional transmission electron microscopy, and (d) 300- and 4-K photoluminescence.

Figure 6. Photoluminescence full-width at half-maximum measured at $4 \mathrm{~K}$ of GaInAsSb grown at $525^{\circ} \mathrm{C}, 550{ }^{\circ} \mathrm{C}$, and $575^{\circ} \mathrm{C}$.

Figure 7. Full-width at half-maximum measured at $4 \mathrm{~K}$ of GaInAsSb grown at different growth rates of $1.2,2.5$, and $5 \mu \mathrm{m} / \mathrm{hr}$ and at a temperature of $550{ }^{\circ} \mathrm{C}[75]$.

Figure 8. 4- and 300-K photoluminescence and high-resolution x-ray diffraction of GaInAsSb grown on (a) (001) $2 \rightarrow(-1-11) A,(b)(001) 2 \rightarrow(1-11) B$, and (c) (001) $2 \rightarrow$ (101) [76].

Figure 9. [110] Cross-sectional transmission electron microscopy image of 0.5-eV GaInAsSb using $\mathrm{g}=<222>2$-beam conditions showing natural superlattice (NSL). The NSL is tilted $10^{\circ}$ from the surface normal, i.e., $4^{\circ}$ in addition to the $6^{\circ}$ miscut angle [78]. 
Figure 10. (a) Experimental and simulated high-resolution $\mathrm{X}$-ray diffraction of and (b) 4-K photoluminescence spectra of 5-period GaInAsSb/GaSb MQW structures grown with various interrupt sequence. The data shown in (a) was taken for a sample with $0.2 \mathrm{~s}$ interrupt.

Figure 11. (a) Experimental and simulated high-resolution x-ray diffraction of and (b) reflectance spectra of a 10-period $\mathrm{AlGaAsSb} / \mathrm{GaSb} \mathrm{DBR}$.

Figure 12. Reflectance spectra of $\mathrm{AlGaAsSb} / \mathrm{GaSb} \mathrm{DBRs}$ grown with different thickness to adjust the stop band.

Figure 13. Inverse PL lifetime versus inverse GaInAsSb thickness of GaInAsSb/AlGaAsSb double heterostructures: ( $\boldsymbol{\square}) \mathrm{GaSb}$ capping layers; ( $\boldsymbol{\Delta}$ ) Al content of $\mathrm{AlGaAsSb}$ is 0.2 ; ( $\mathrm{O}) \mathrm{Al}$ content of $\mathrm{AlGaAsSb}$ is 0.25 ; and (•) $\mathrm{Al}$ content of $\mathrm{AlGaAsSb}$ is $0.3[86,87]$.

Figure 14. Schematic structure of wafer-bonded GaInAsSb TPV cells with monolithic interconnections on a SI GaAs handle wafer.

Figure 15. Photoluminescence (PL) and PL decay of wafer bonded and control 0.55-eV GaInAsSb lifetime structures.

Figure 16. Semi-logarithmic plot of $\mathrm{J}_{\mathrm{sc}}$ versus $\mathrm{V}_{\mathrm{oc}}$ for singe cell, 2-cell, and 10-cell interconnected GaInAsSb devices [64]. 

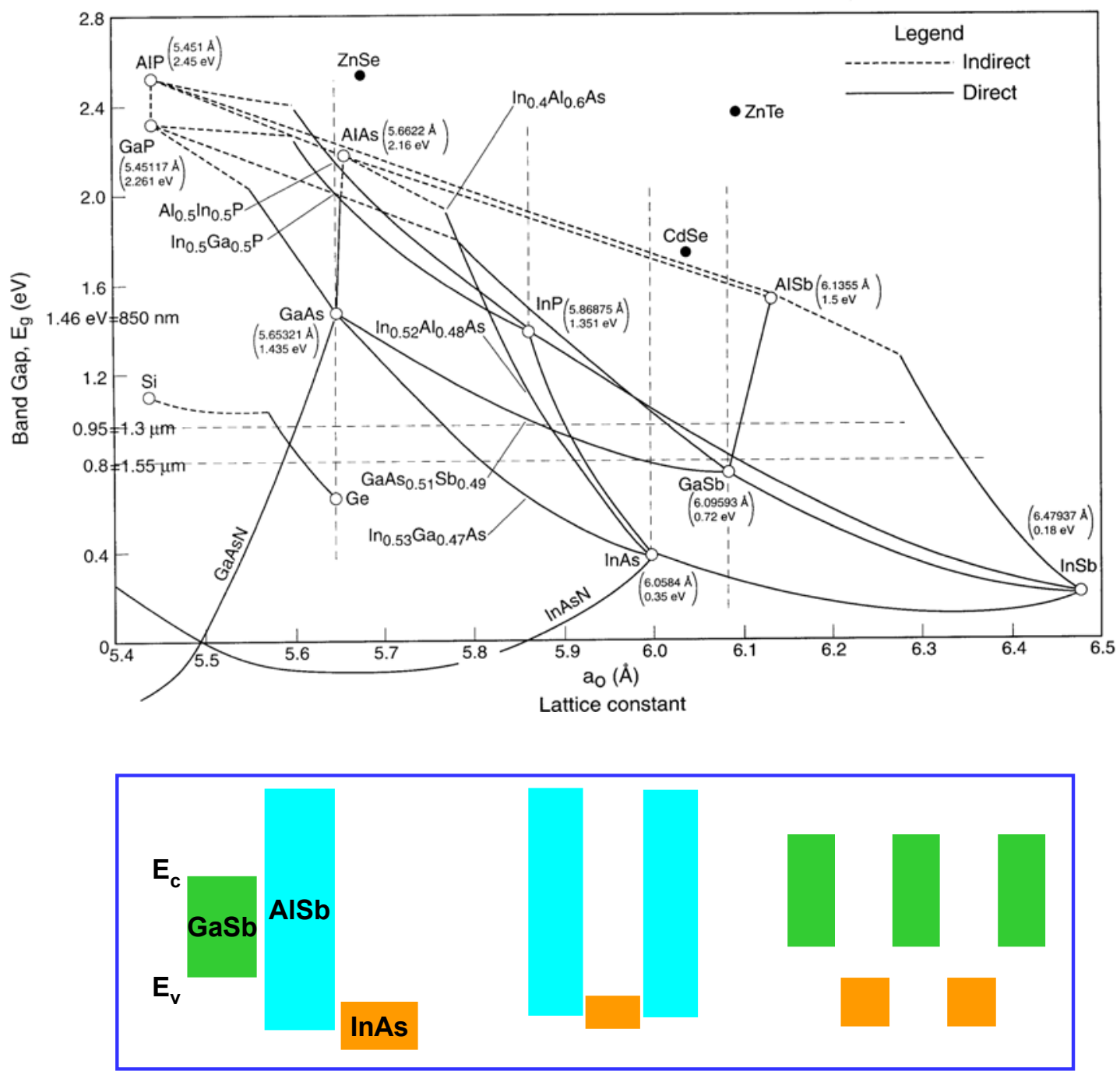

Figure 1 


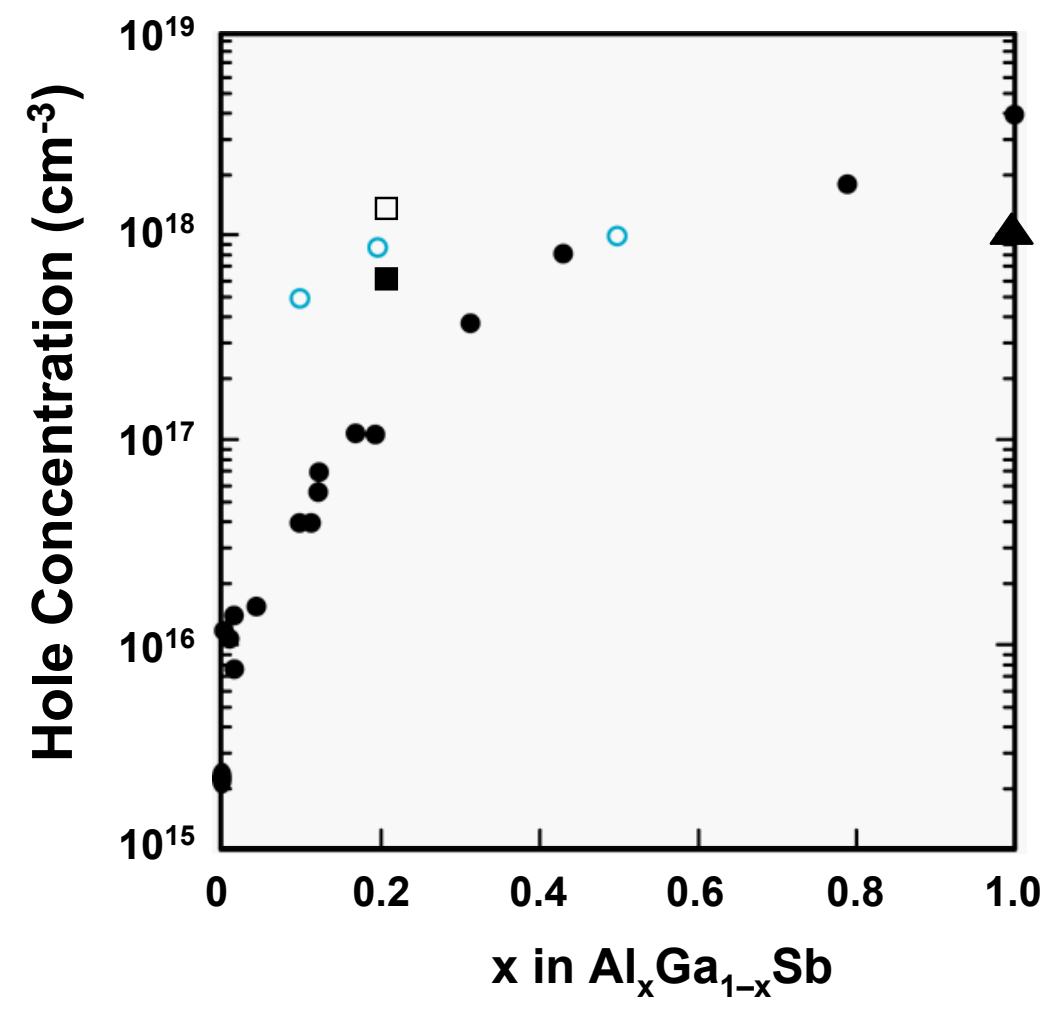

(a)

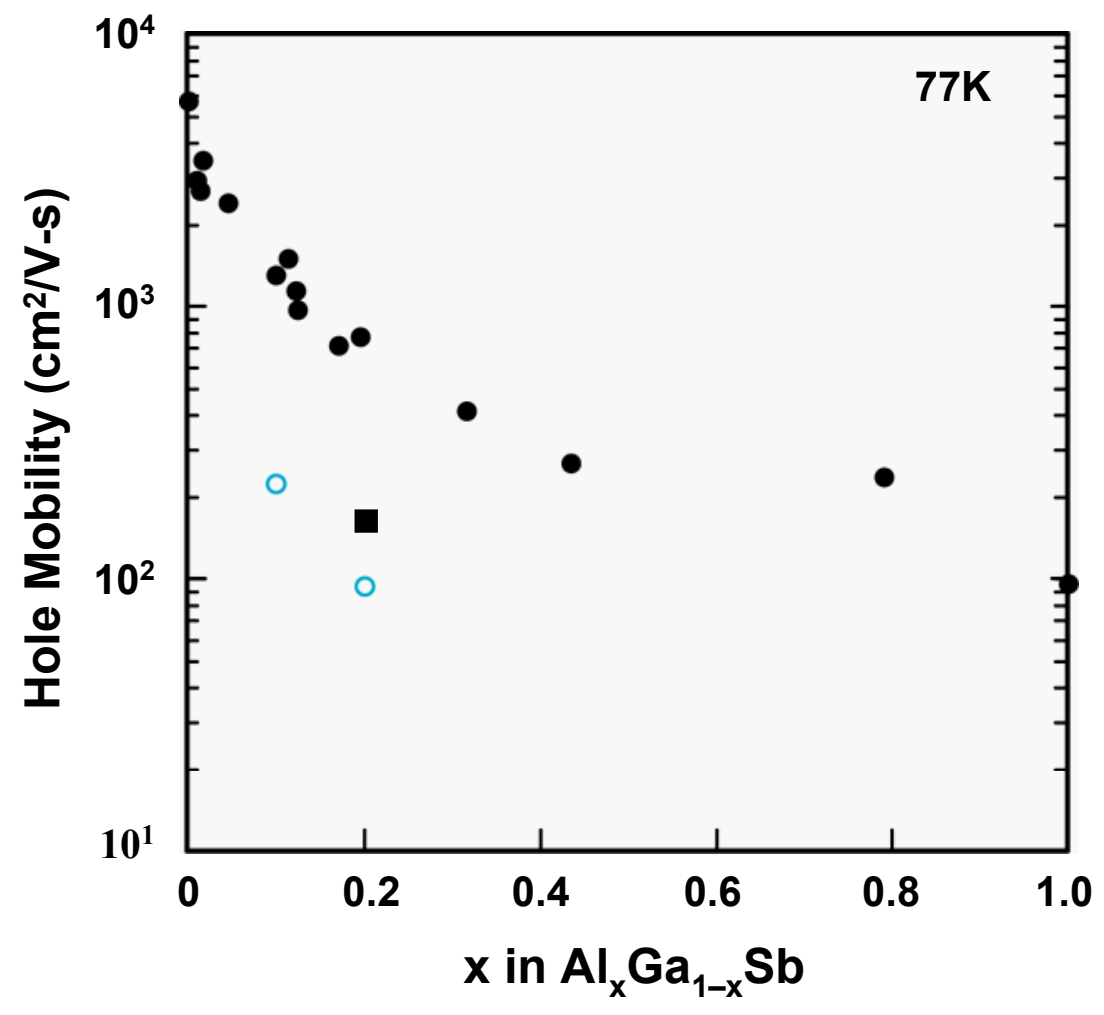

(b)

Figure 2 


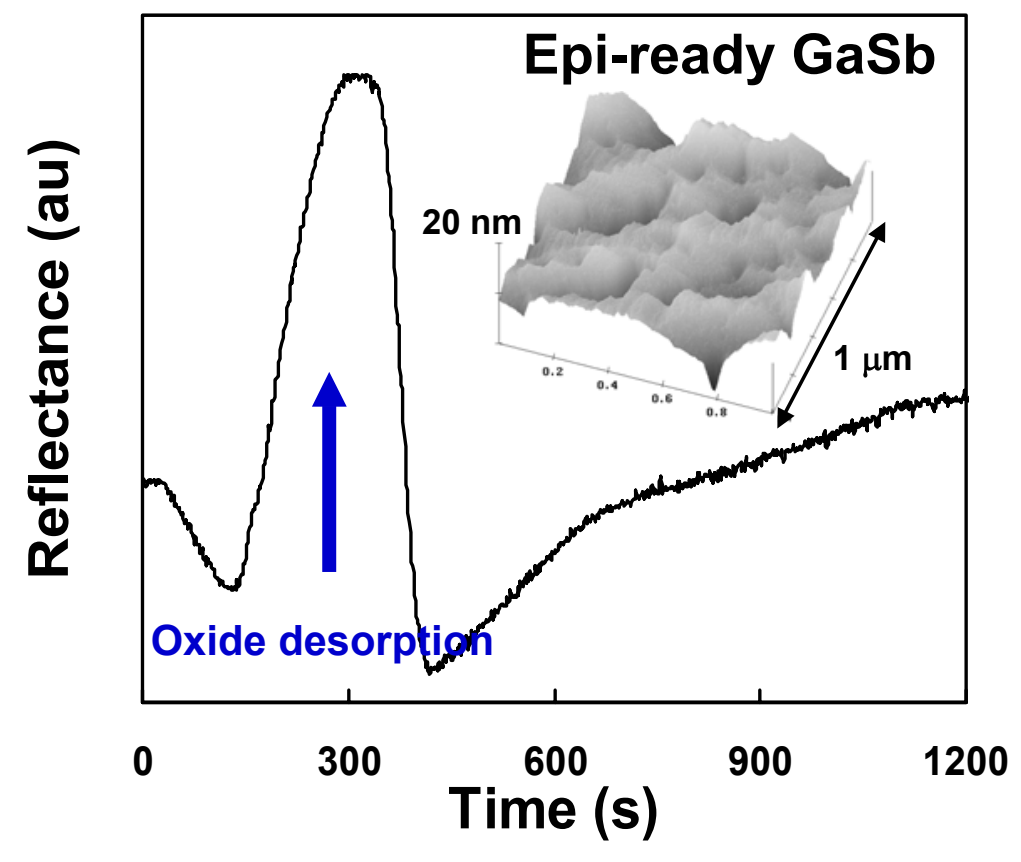

(a)

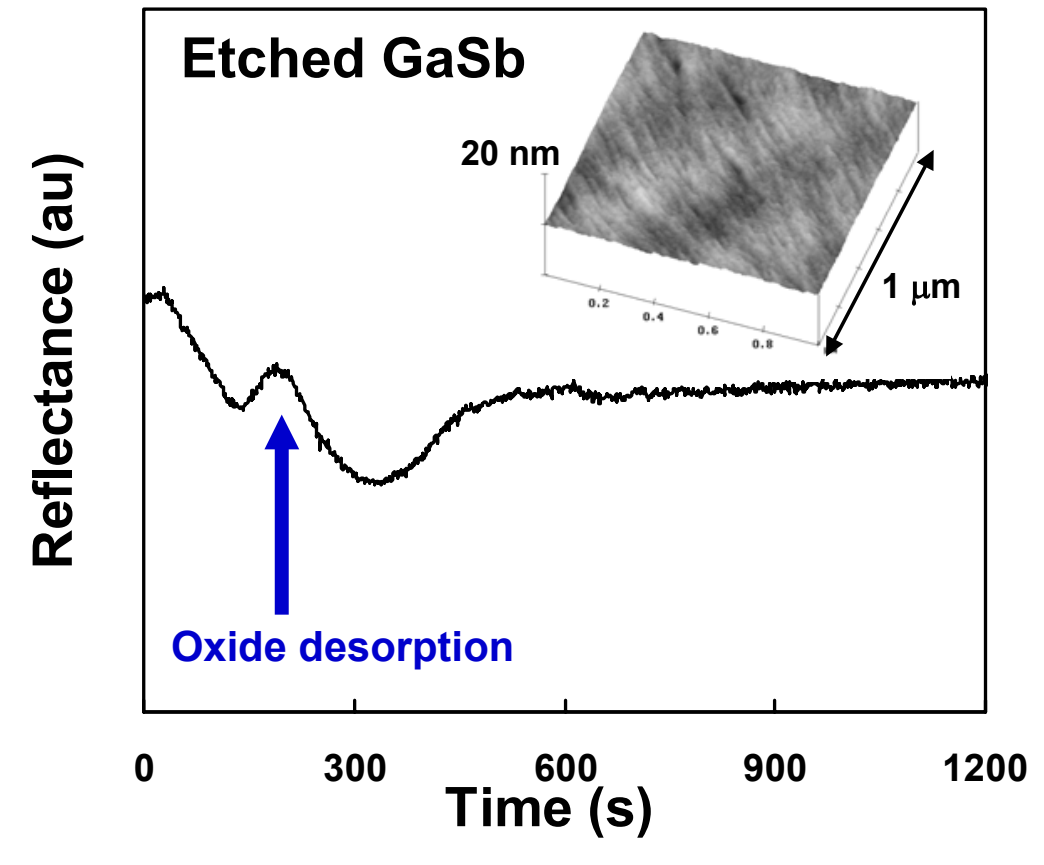

(b)

Figure 3 
(a)

\section{AFM}

$0.2 \mathrm{~nm}$ rms

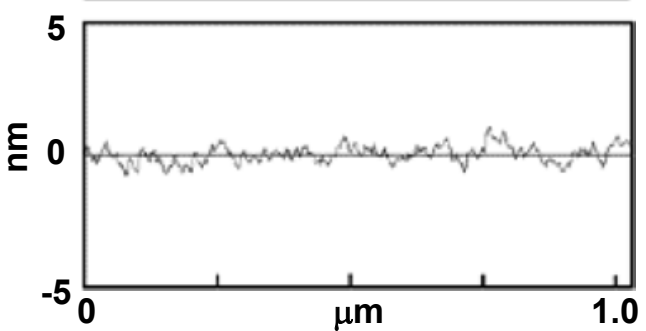

X-TEM

Figure 4

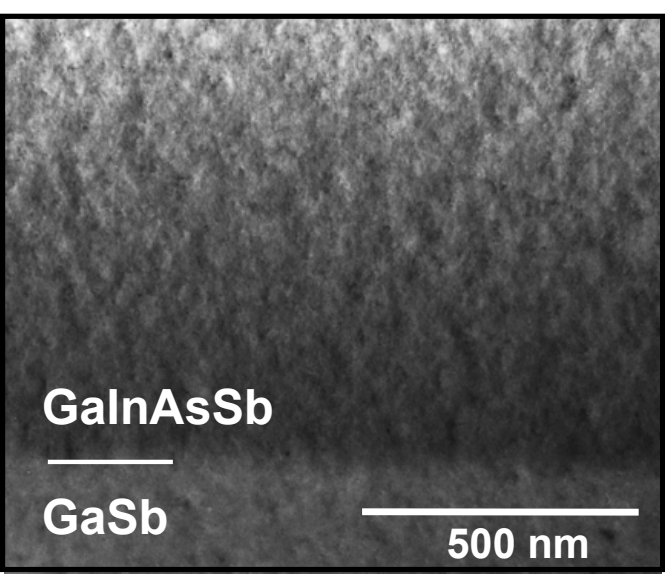

(c) (b)

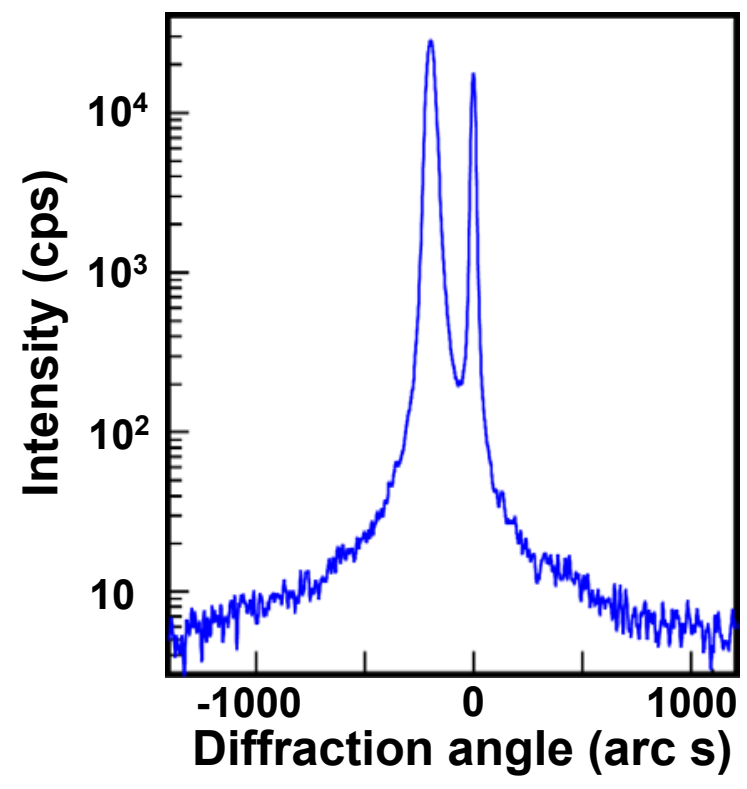

XRD

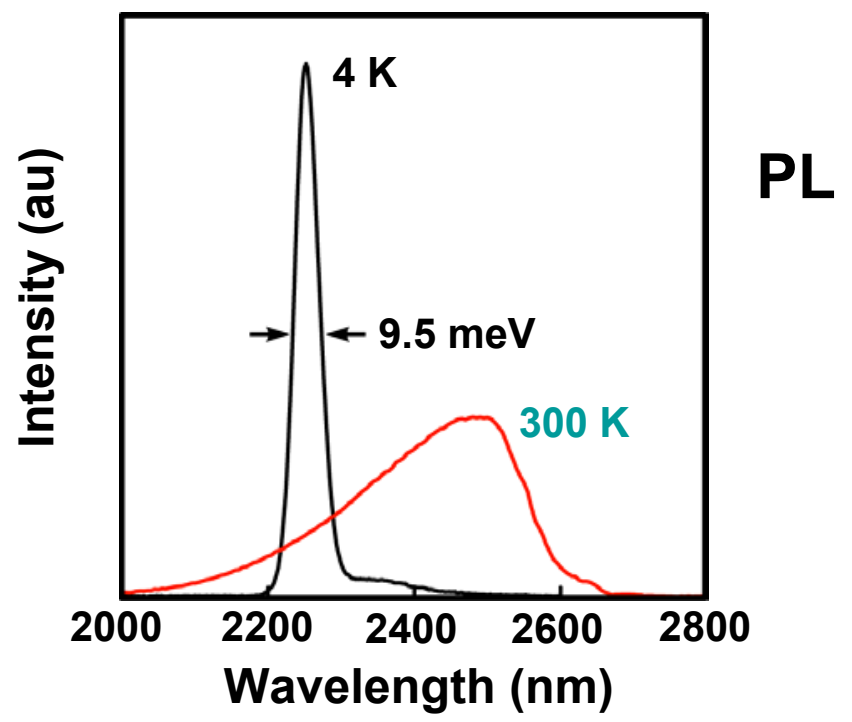

(d) 
(a)

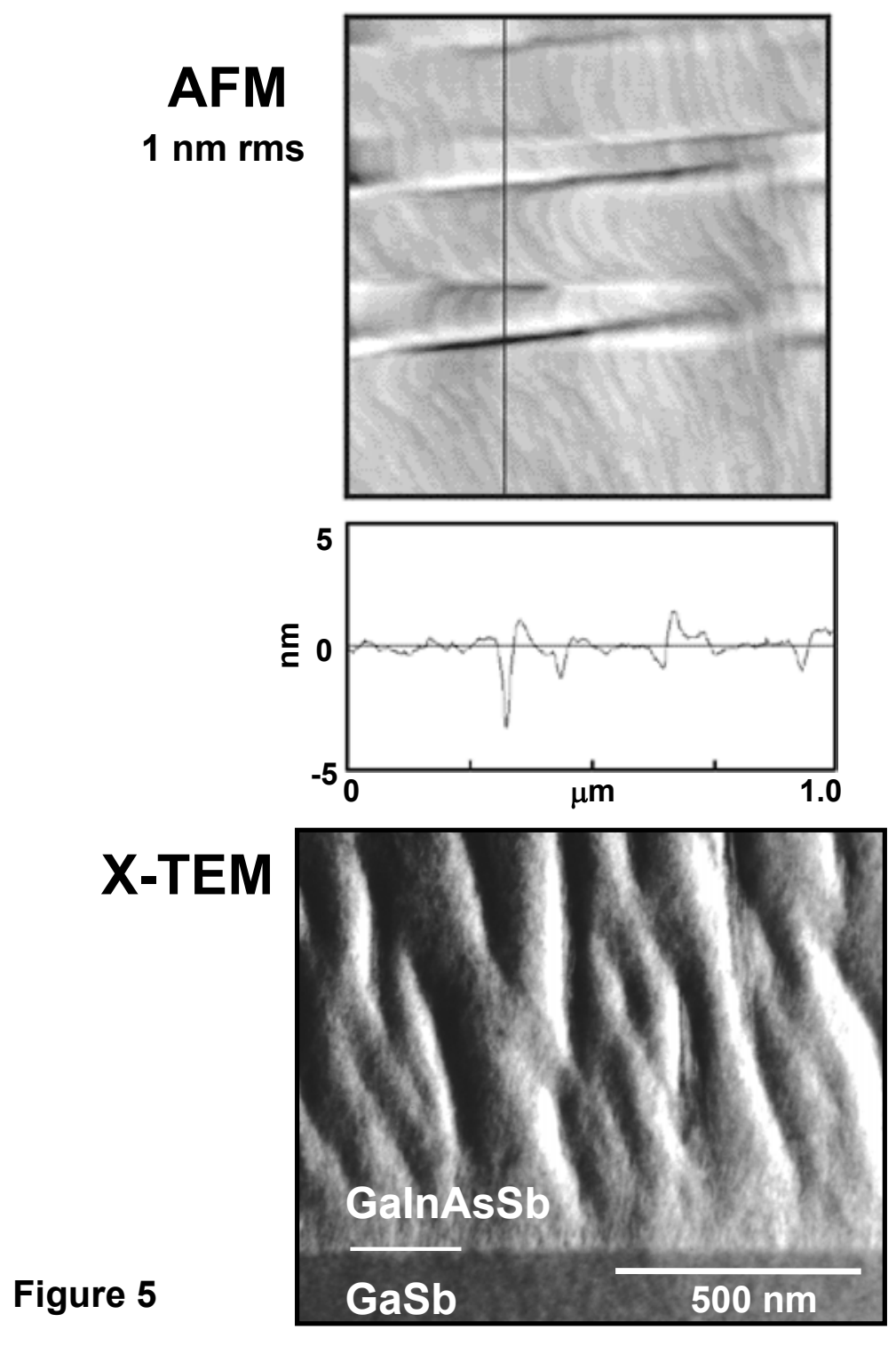

(c) (b)
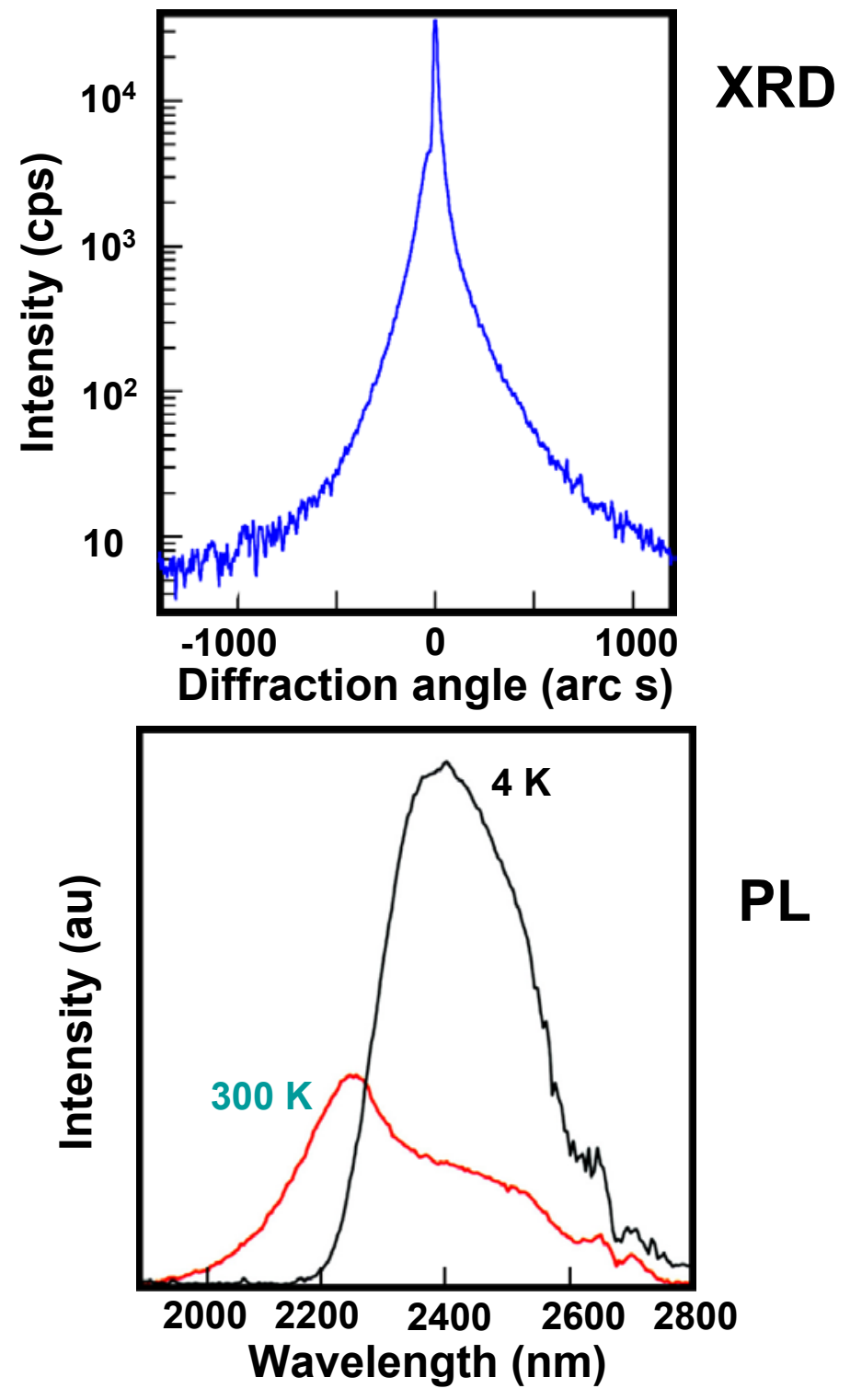

(d) 


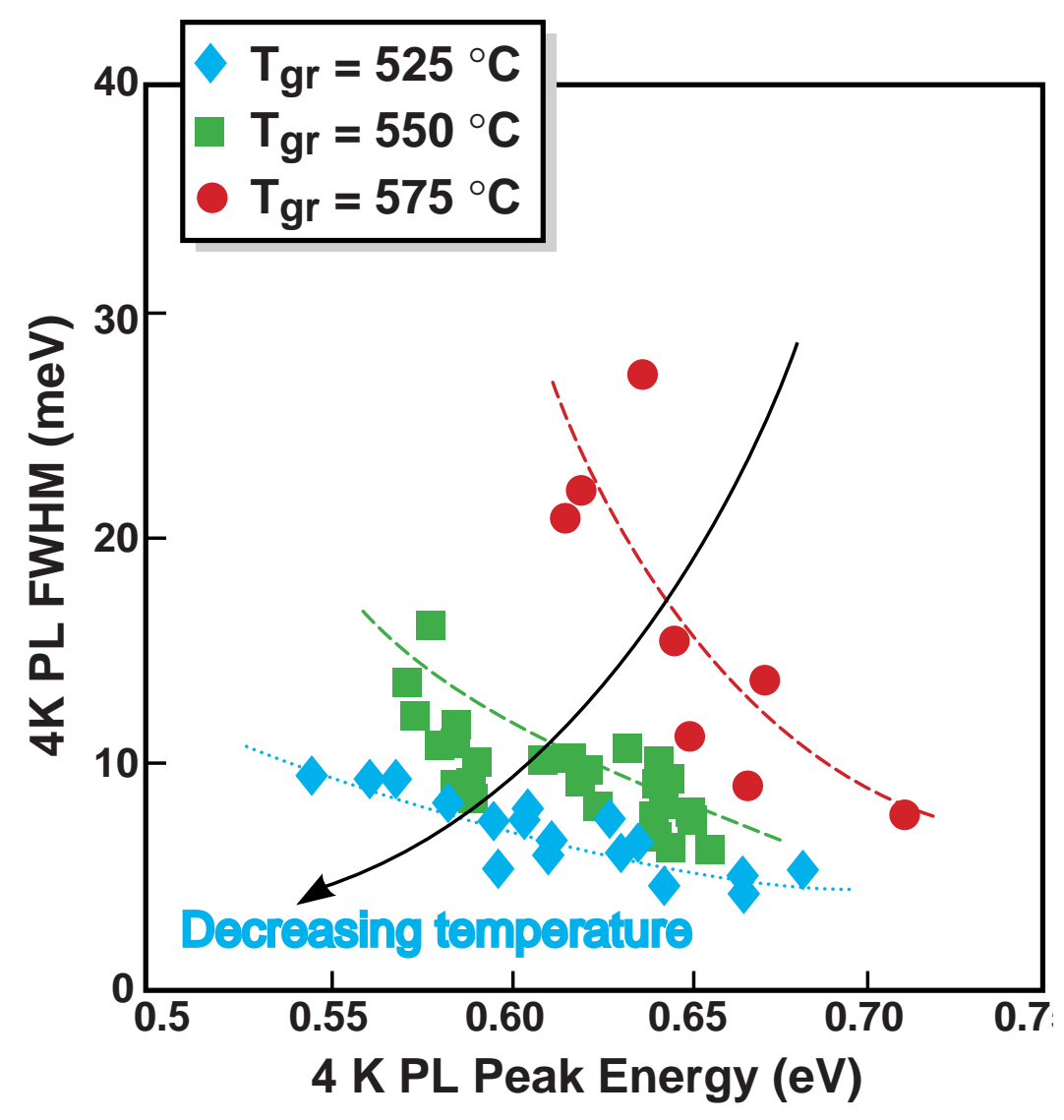

Figure 6 


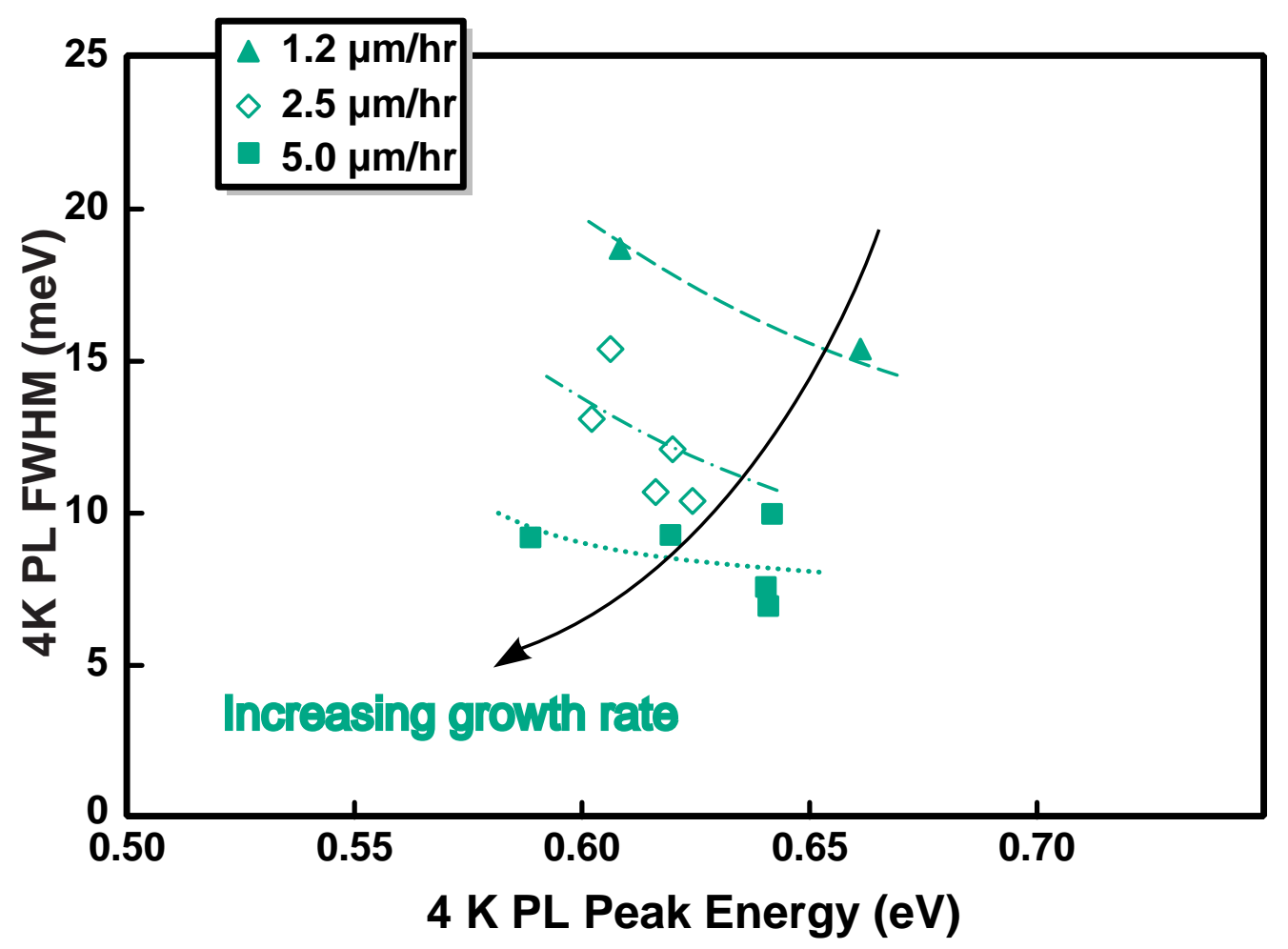

Figure 7 


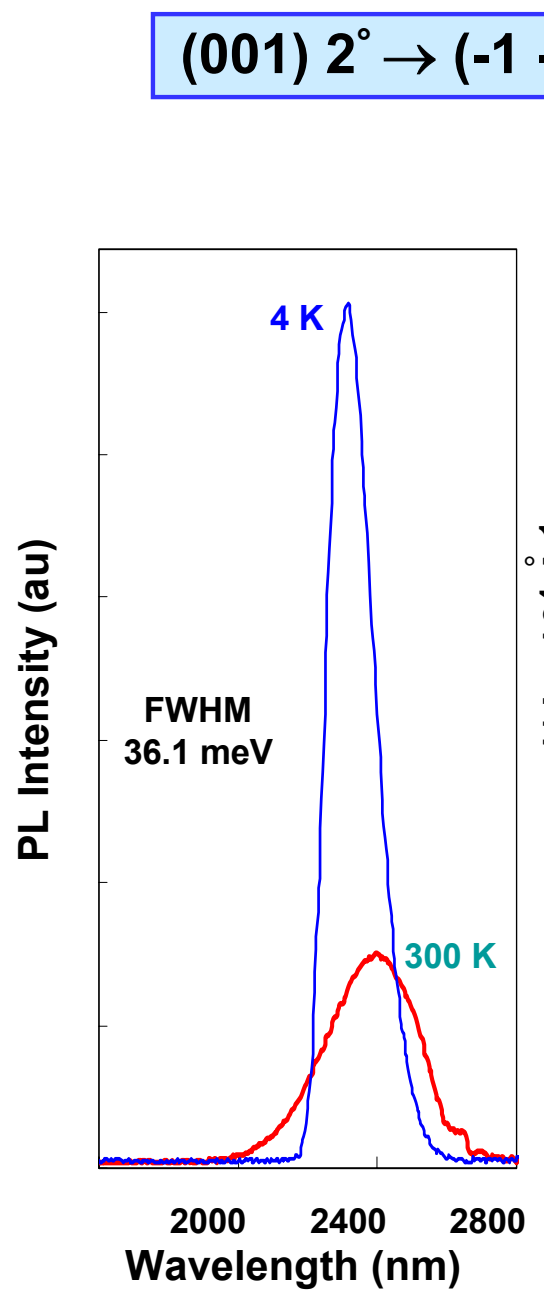

(a)

a)
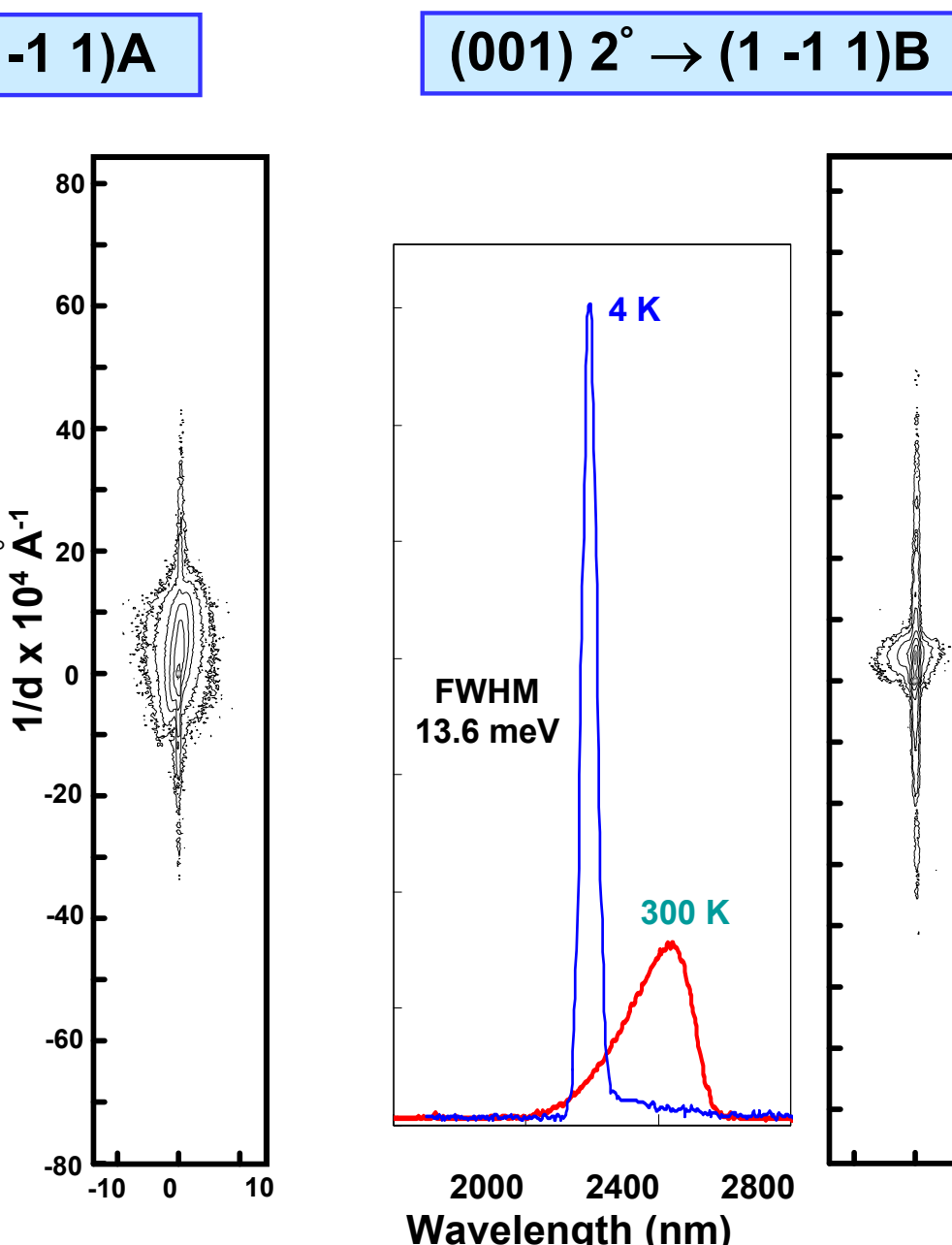

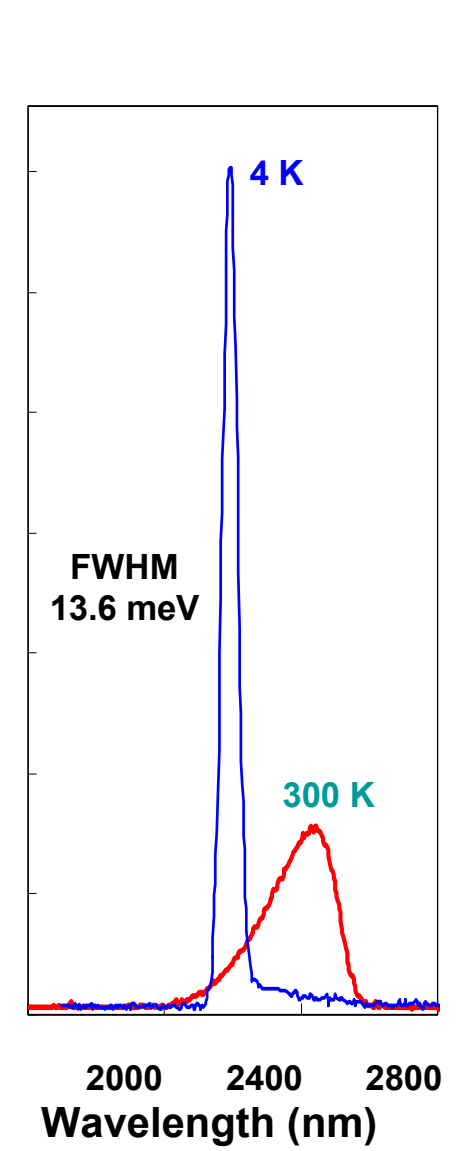

(b)

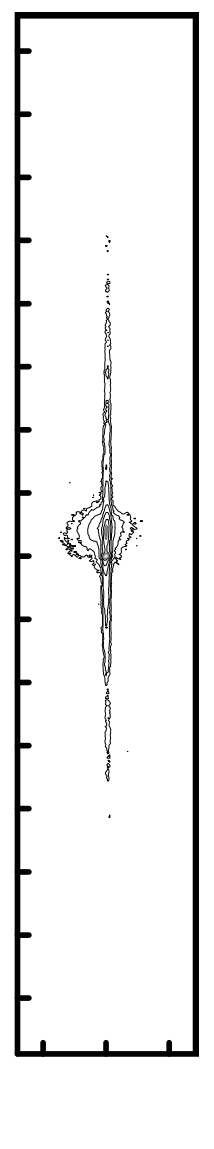

avelength (nm)

(c)

Figure 8 


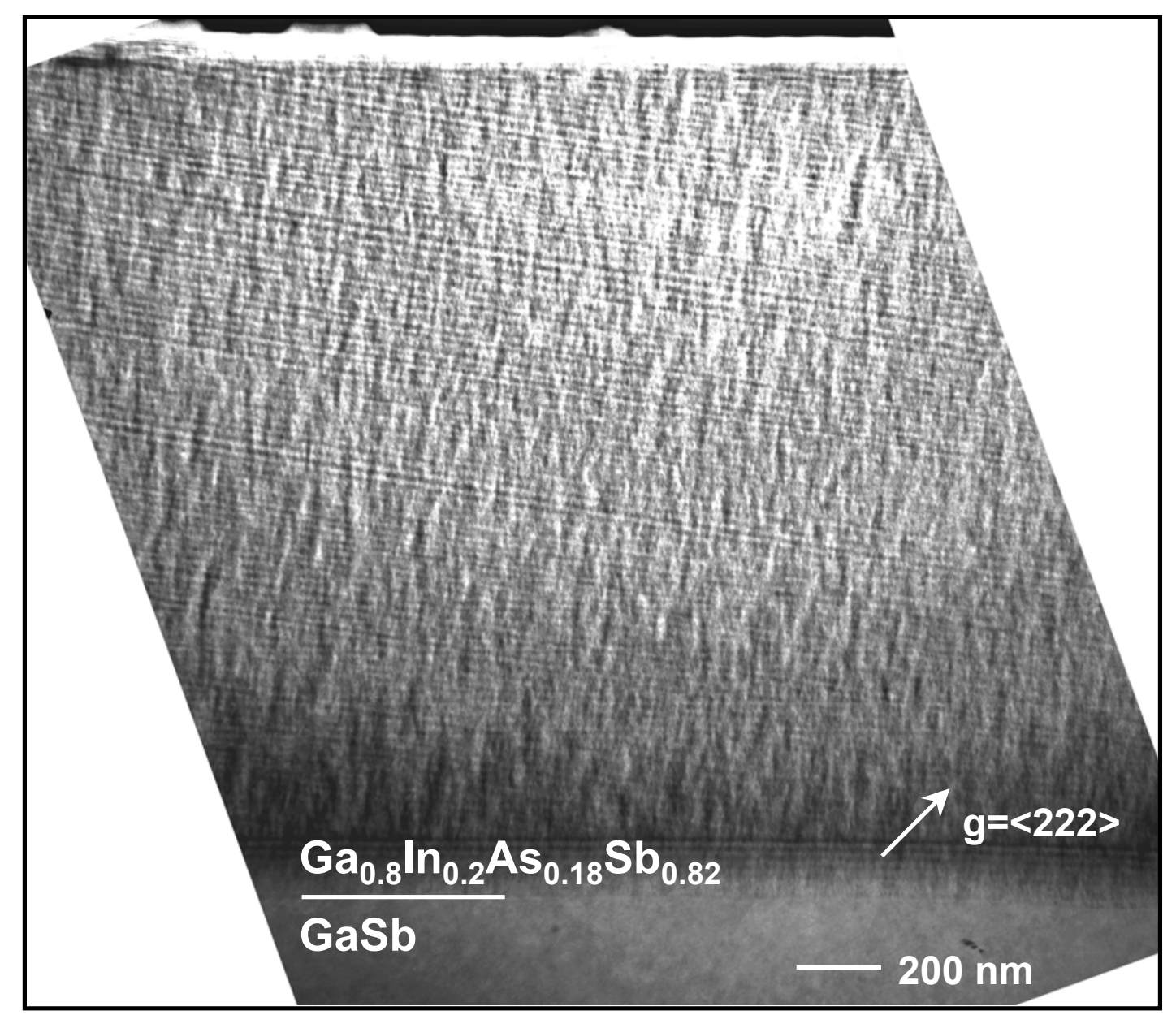

$\left[0016^{\circ} \mathrm{B}\right.$

$\longleftrightarrow[\overline{1} 10]$

Figure 9 


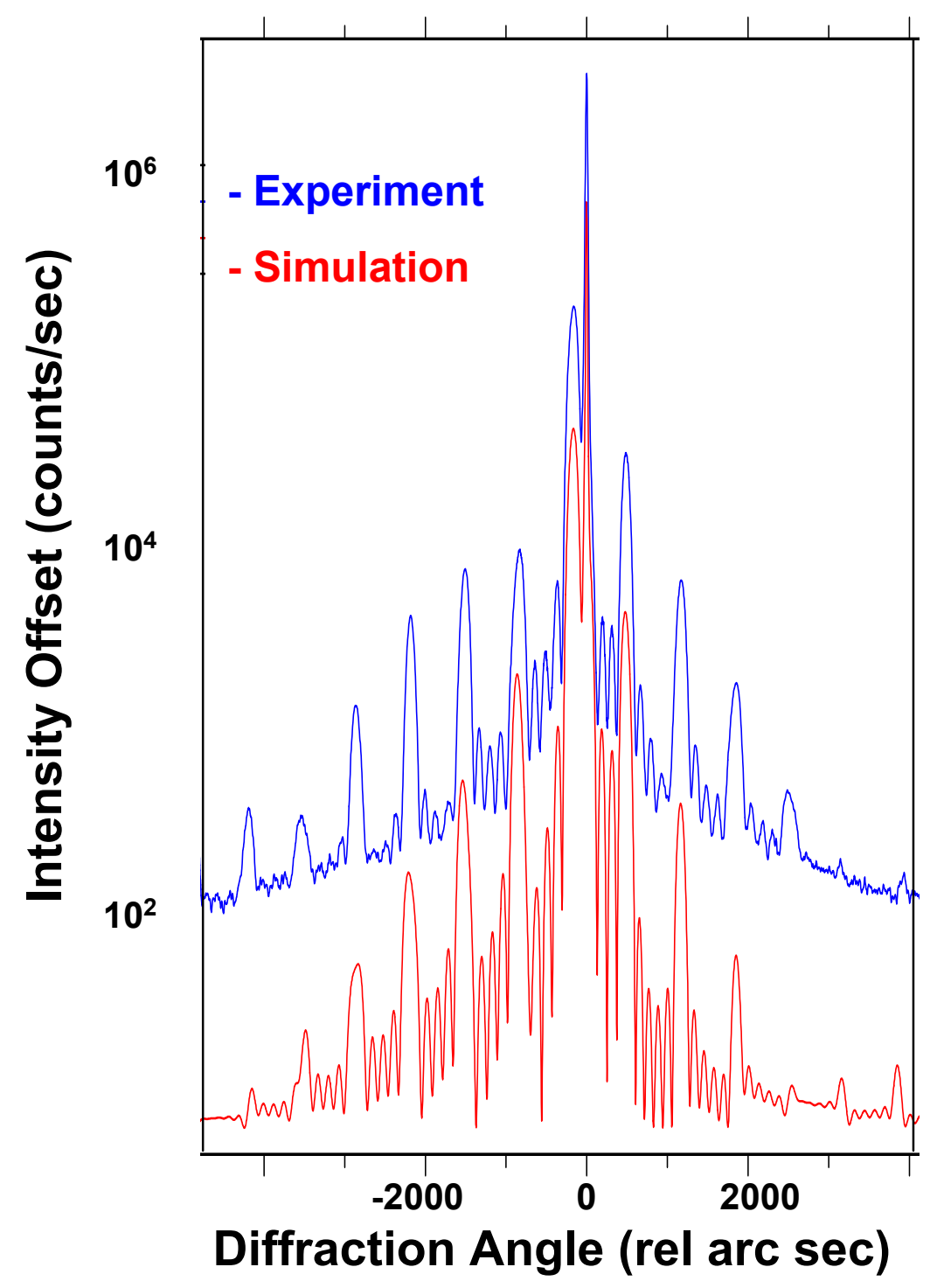

Figure 10

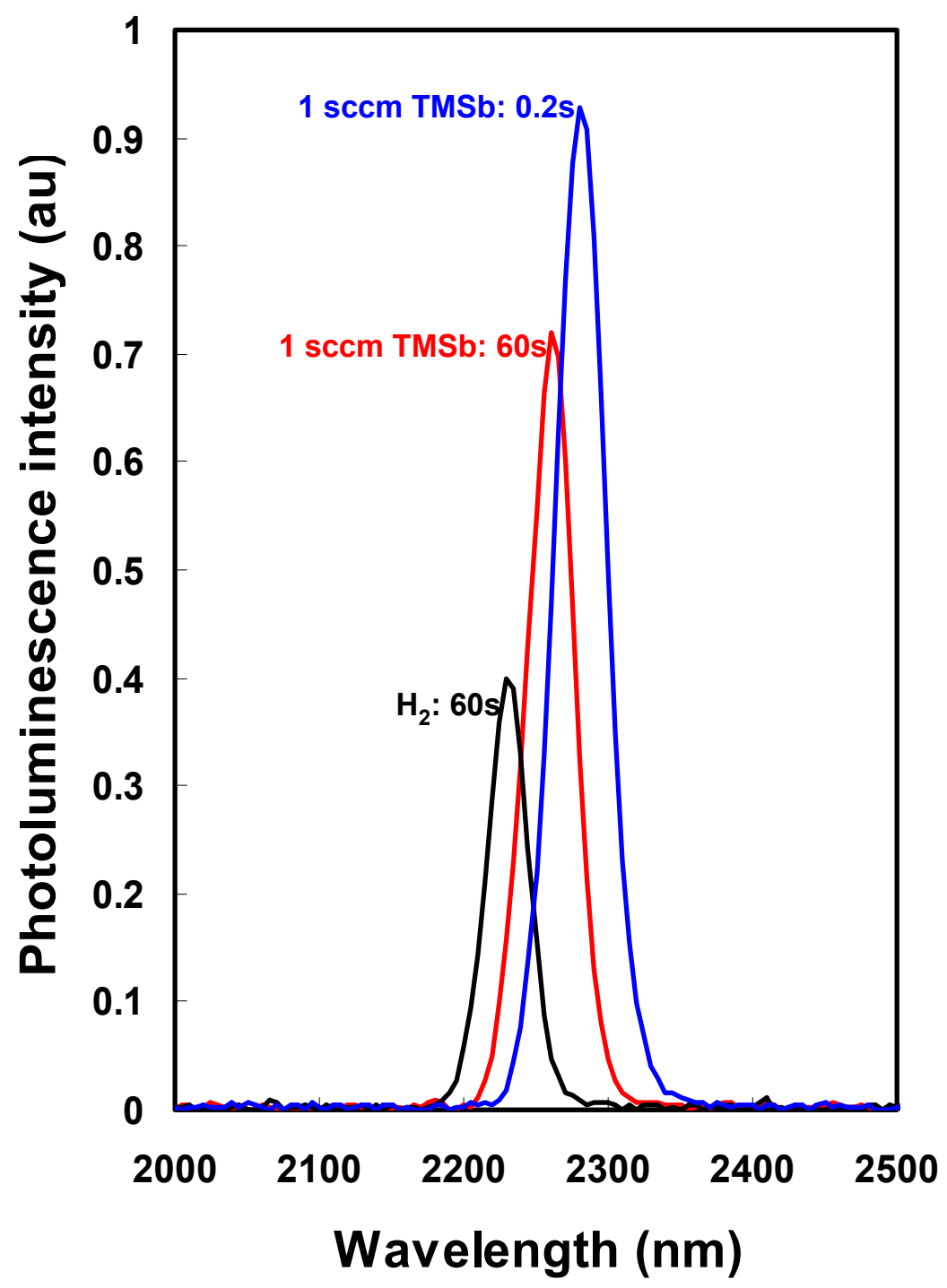

(b) 


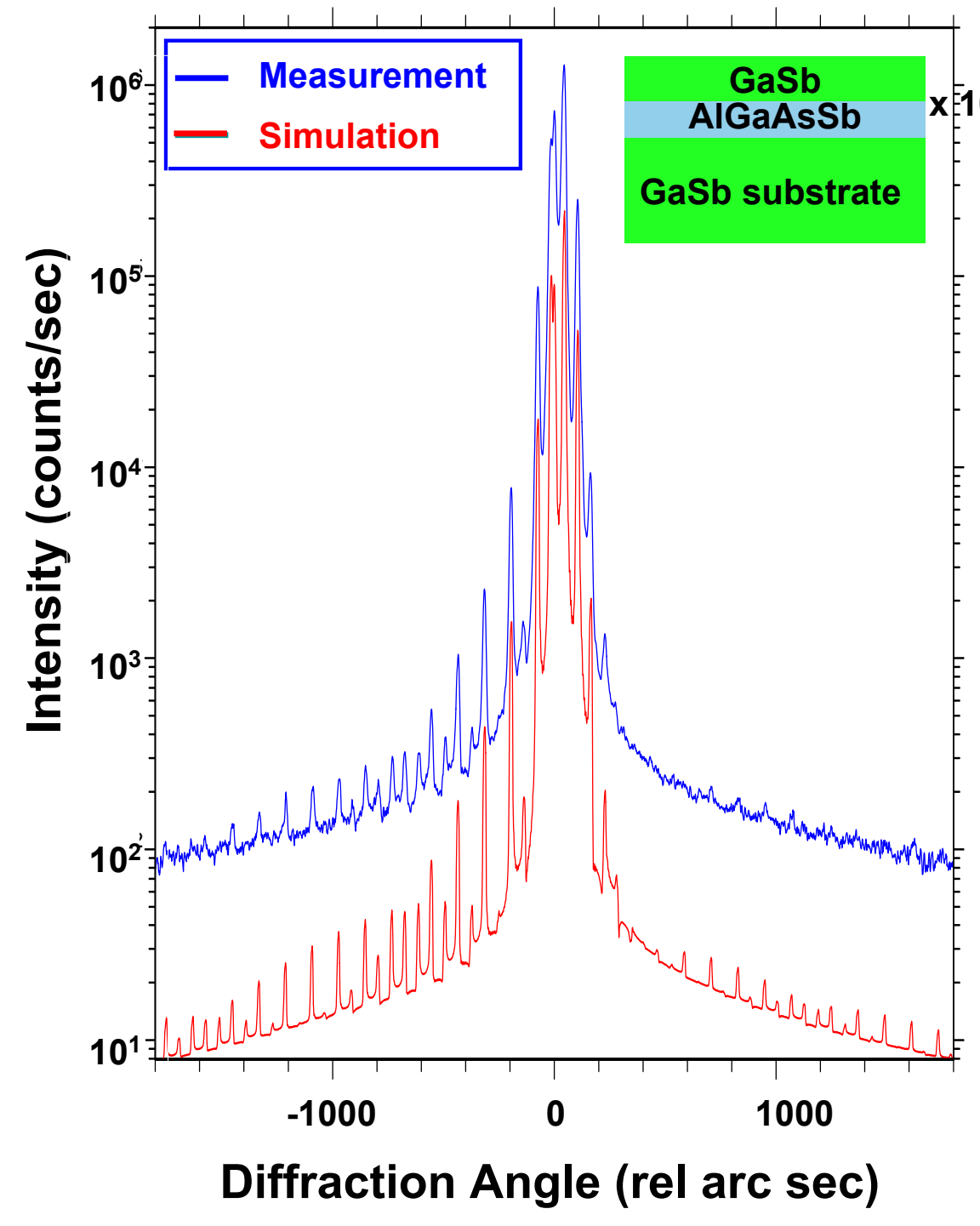

Figure 11

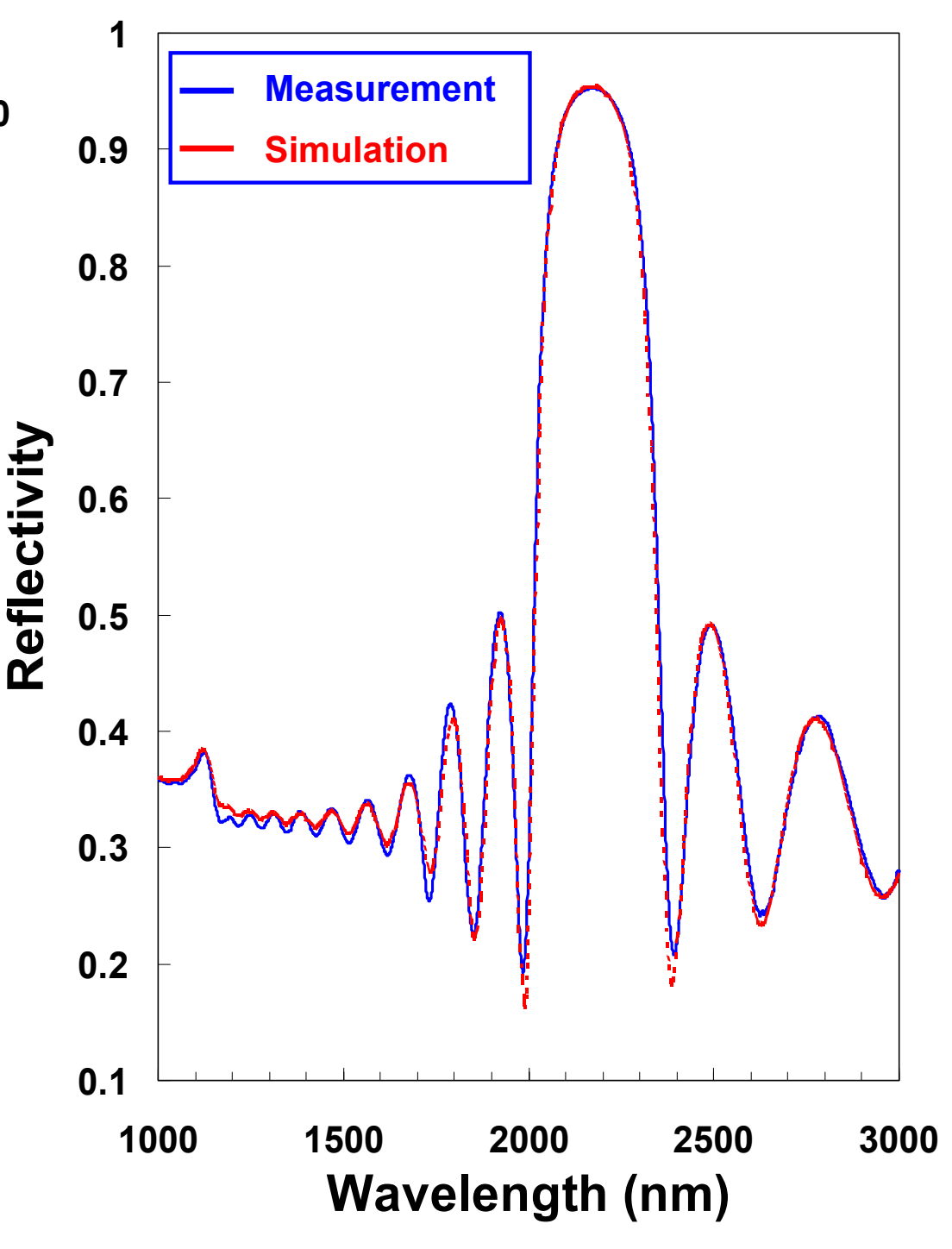

(b) 


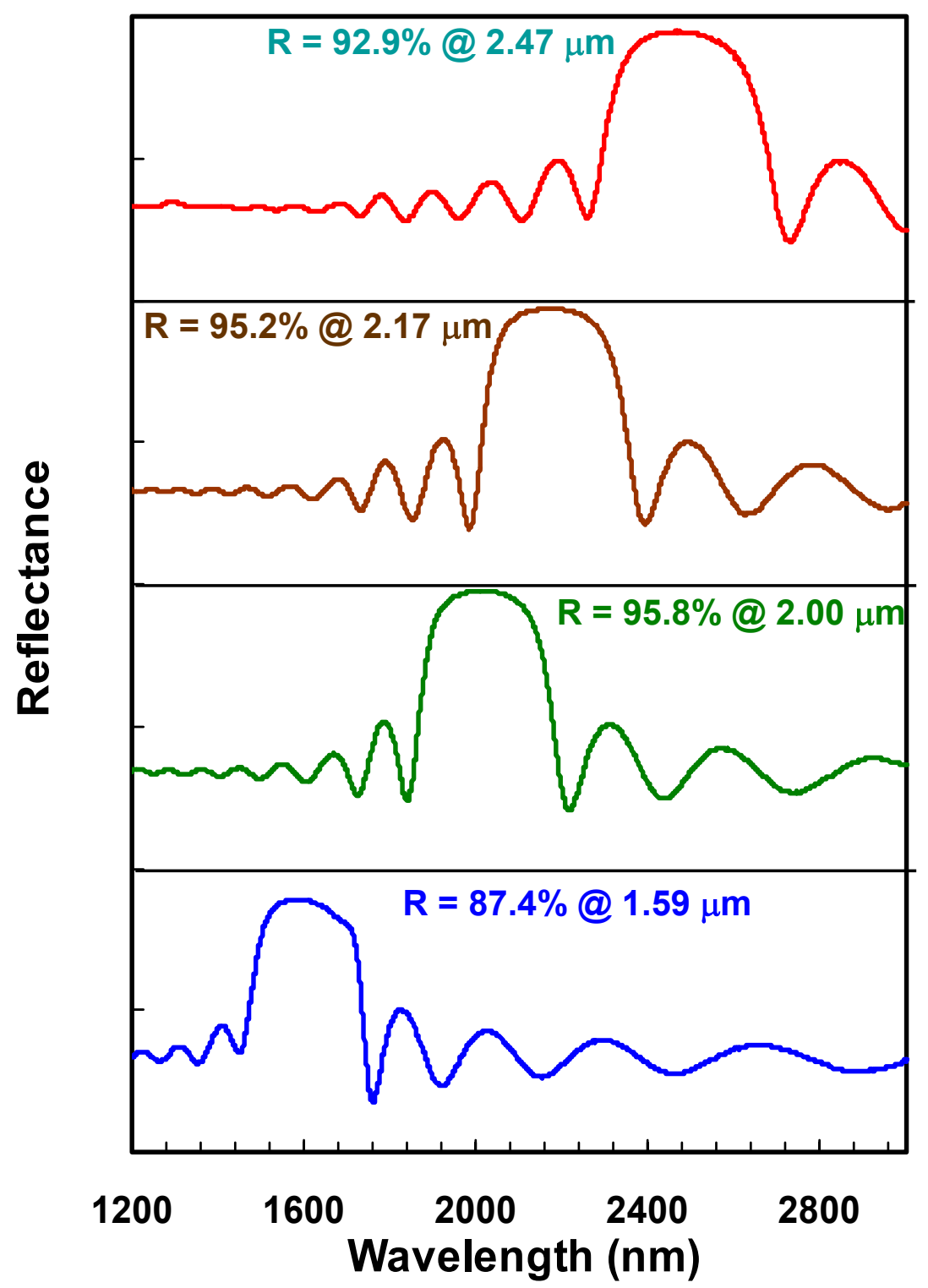




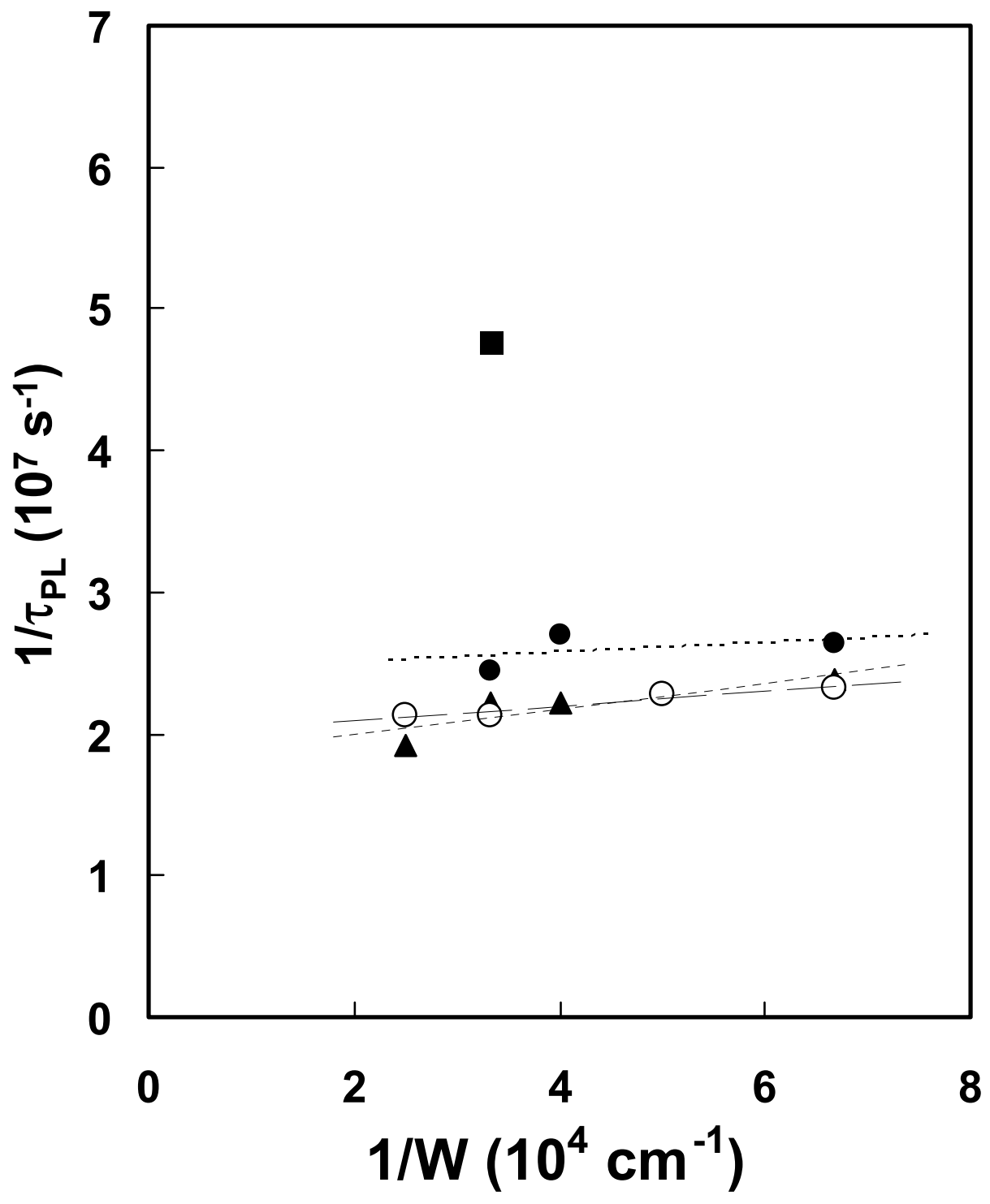

Figure 13 


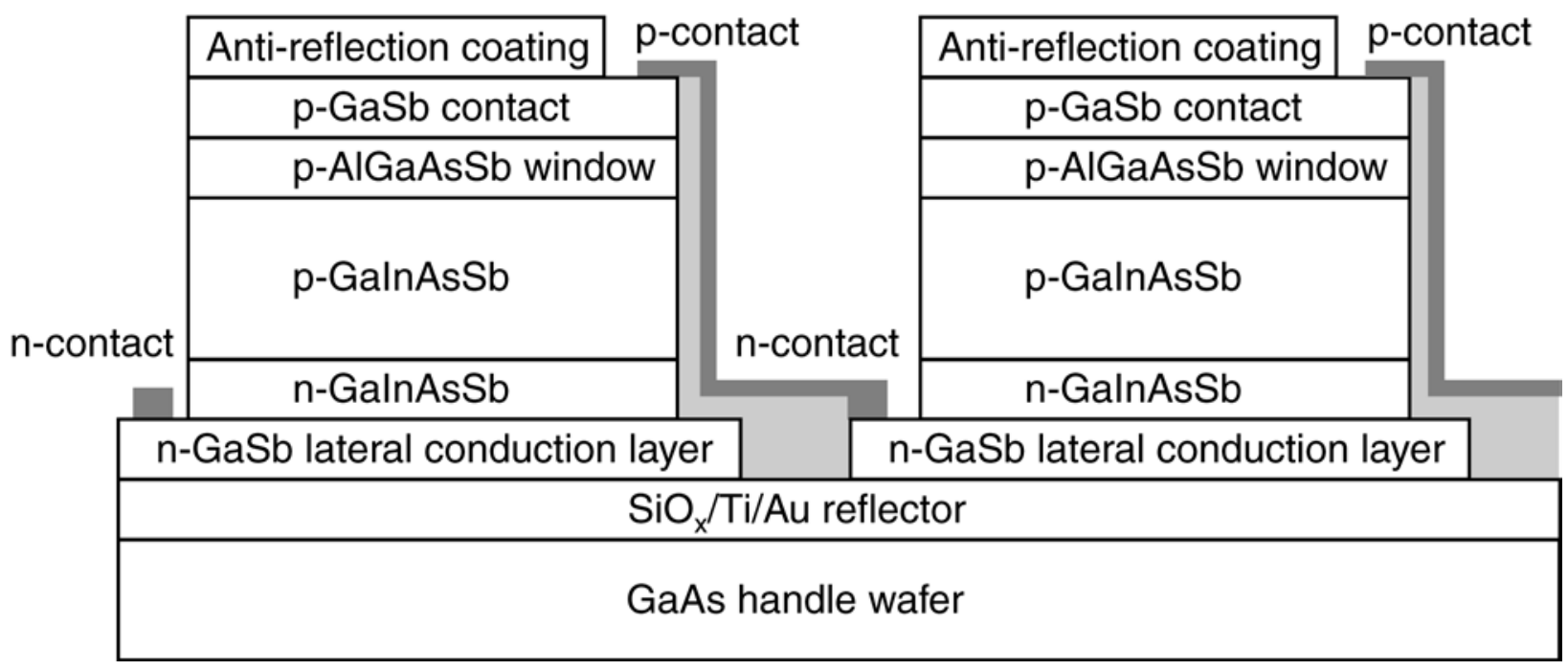

Figure 14 


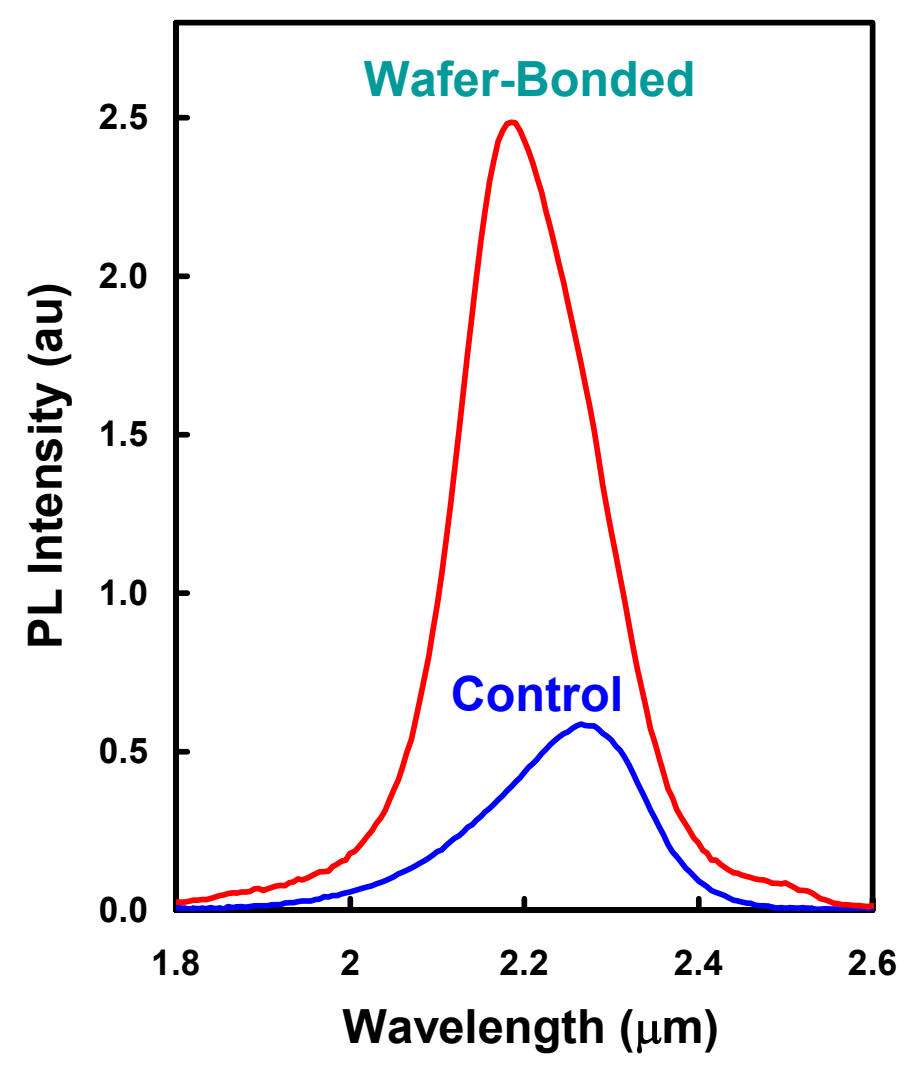

(a)

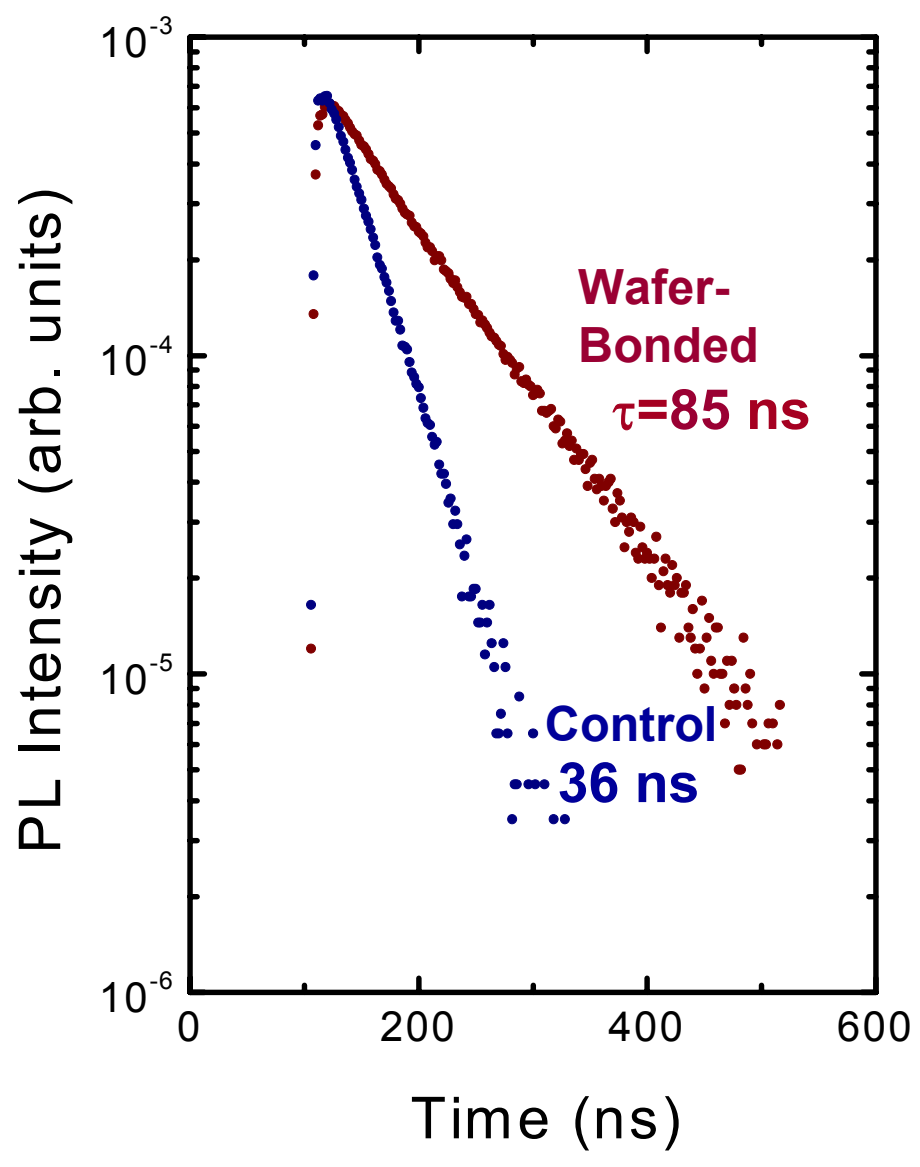

(b)

Figure 15 


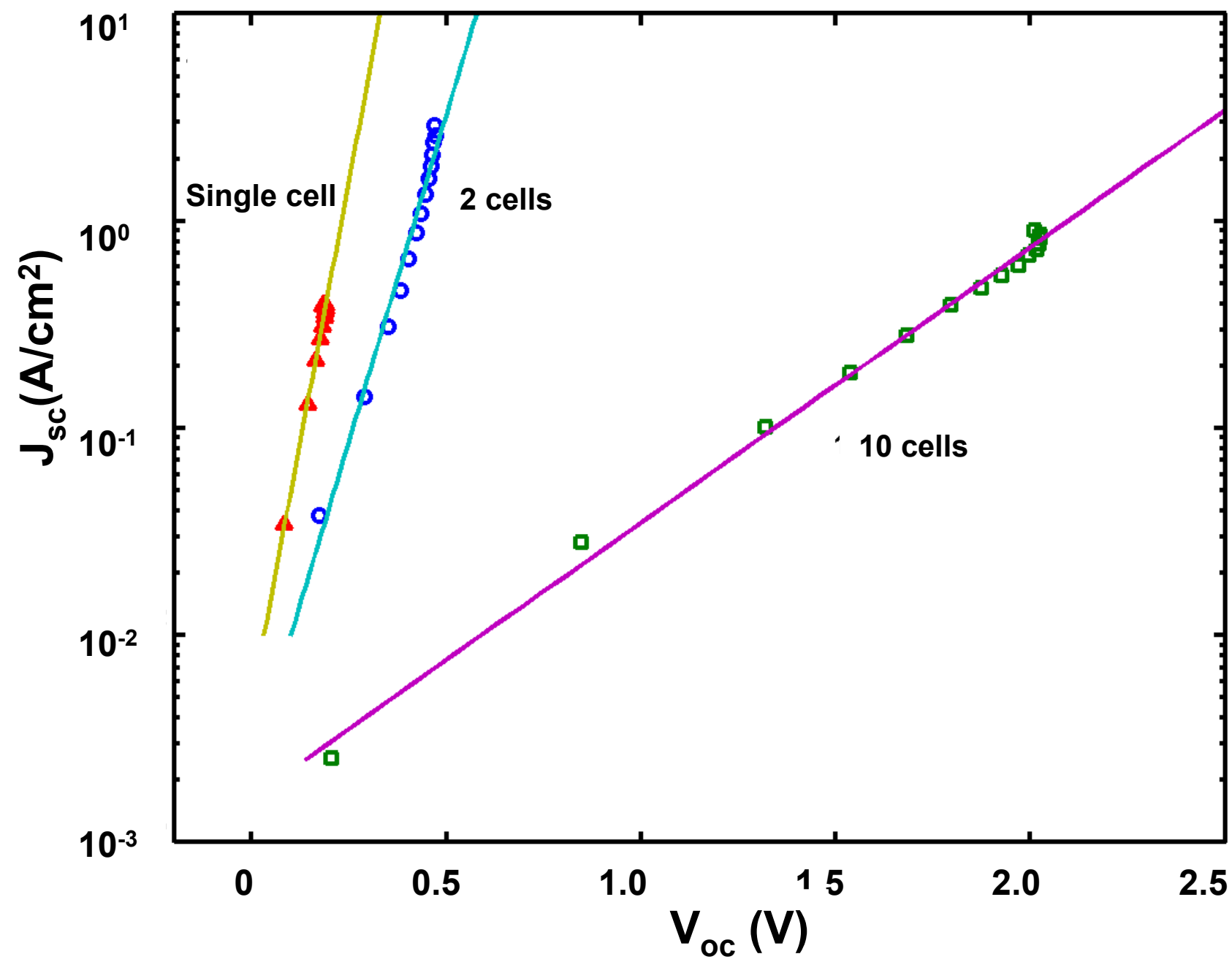

Figure 16 